\title{
Entity and Event Coercion in a Symbolic Theory of Syntax
}

\author{
Laura A. Michaelis \\ University of Colorado at Boulder
}

\section{Introduction}

Where does sentence meaning come from? Leaving aside the inference strategies targeted by the Gricean paradigm, formal models of the syntax-semantics interface have supplied a single answer to this question: the words of the sentence and the frames which those words project. Since word combination in formal theory is inextricably tied to phrase building, the drivers of sentence semantics are not simply words but, more particularly, the heads of syntactic projections. The assumption that the licensing of sisterhood relations is the unique privilege of lexical heads is woven into the formal conventions of formal theory, e.g., phrase-structure rules like those in (1), in which the 'optionality' of complements, specifiers and adjuncts is defined over a set of lexical classes distinguished by their projection behaviors:

$$
\begin{array}{ll}
\text { a. } & \mathrm{VP} \rightarrow \mathrm{V}(\mathrm{NP})(\mathrm{PP}) \\
\text { b. } & \mathrm{NP} \rightarrow(\text { determiner }) \mathrm{N}
\end{array}
$$

Models of sentence meaning based on lexical projection provide a straightforward picture of the syntax-semantics interface: while words determine WHAT a sentence means, rules of morphosyntactic combination determine HOW a sentence means. While rules of syntactic combination assemble heads and their dependent elements into phrases, they play no role in either the licensing or construal of arguments. It is apparent, however, that the syntax-semantics mapping is less tidy than the foregoing statement would imply. In particular, the identification of licensors with syntactic heads cannot always be maintained. This is shown by the following examples, in which the projection properties of the boldfaced items are distorted in various ways. These distortions involve, respectively, nominal morphosyntax (2), verbal thematic structure (3), and those aspects of verbal morphosyntax which are determined by the aspectual class of the verbal projection or SITUATION RADICAL:

\section{(2) Nominal Morphosyntax}



a. Give me some pillow.
b. They sampled some wines.
c. She had a beer.

\section{(3) Semantic Frame}

a. Down at the harbor there is teal-green clubhouse for socializing and parties. Beside it sparkles the community pool. (Vanity Fair 8/01).

b. When a visitor passes through the village, young lamas stop picking up trash to mug for the camera. A gruff 'police monk' barks them back to work. (Newsweek 10/13/97)

\section{(4) Aspectual Morphosyntax}
a. She liked him in a minute.
b. I'm feeding him a line and he's believing every word.
c. She washes the car.

In (2a), a word which denotes a bounded entity, pillow, is embedded in the morphosyntactic frame ordinarily projected by a mass noun, while in (2b-c) the inverse is the case. In (3), two monovalent verbs, sparkle and bark are embedded, respectively, in bivalent frame comprising a location and a theme and a trivalent frame, comprising an agent, a theme and a goal. In (4a-b) stative situation radicals are combined with aspectual operators which logically require tenseless propositions denoting events. In (4a), the state radical She like- him combines with a frame adverbial (in a minute), which is logically compatible only with those predications which do not entail downward to subintervals, i.e., telic events (Herweg 1991). In (4b), the state radical $\mathrm{He}$ believe- every word combines with Progressive morphology. This combination is unpredicted by verbal aspect. Since the Progressive maps events to medial states, it appears to apply vacuously in this context (see Vlach 1981, Langacker 1987, Herweg 1991, De Swart 1998). In (4c), an event radical, She wash- the car, combines with Present inflection. While this combination is widely attested it too involves a distortion of verbal aspect: (4c) does not denote a unique event, as would its simple Past counterpart. As a momentaneous 'sampling' device, the Present cannot accommodate the positive temporal profile of an event. Instead, the Present appears to index the class of stative situations, e.g., a state of the world in which car-washing takes places at regular intervals. 
A model of the syntax-semantic interface based solely upon lexical-head licensing would, of course, fail to account for the fact that all of the examples in (1-3) have coherent, consistent interpretations. For example, the verb bark in (3b) is uniformly construed as denoting (metaphorical) caused motion, while the situation radical I like- him in (4a) receives an inchoative interpretation. Although these interpretive effects might be dismissed as the products of manner- or relevance-based implicatures, the relevant implications do not obviously qualify as generalized implicata: because they are based on the presence of specific lexical items, these implications, like conventional implicatures, are neither detachable nor defeasible. The foregoing examples therefore suggest that there is not in fact a single source of sentence meaning: conceptual content comes not only from words but also from an inferential procedure which bridges semantic gaps in morphosyntax. I will refer to this procedure as IMPLICIT TYPE-SHIFTING, reserving the more widely used terms COERCION and COERCION EFFECT to refer to the enriched representations produced by the reconciliation mechanism in question. Our exploration of implicit type-shifting thus far enables us to draw the following three generalizations:

- First, semantic operators can apply even in the absence of an appropriate situation-type argument, since the argument can adapt to the requirements of the functor. This fact is difficult to model in a noncircular way, since a given operator must not only operate on the output of an inference rule, but also trigger the very inference rule which enables it to apply.

- Second, the patterns which trigger coercion effects do not have a uniform syntactic characterization. The coercion trigger may be a syntactic head, as in the case of the Progressive, where the auxiliary head be selects for a participial complement of the appropriate aspectual class, forcing a dynamic reading in the 'mismatch' condition (4b). The coercion trigger may be a specifier like some in (2b), which selects for a noun whose denotatum is a mass. Finally, it may be an open schema, as in (3), where the relevant sceneconstrual properties follow from the presence of specific grammatical functions, rather than being attributable to a given verb or argument. 
- Third, coercion effects are produced by both TYPE-SHIFTING schemas and TYPE-SENSITIVE schemas. An example of the former is the Progressive construction. An example of the latter is the Frame Adverbial construction (3a).

Coercion effects appear to indicate a modular grammatical architecture, in which the process of semantic composition may add meanings absent in the syntax in order to ensure that various functors, e.g., the indefinite article, receive suitable arguments. One such model, proposed independently by both Jackendoff $(1990,1997)$ and De Swart (1998), involves the interpolation of coercion operators in semantic structure. In the case of (2c), for example, a specific coercion operator would be used to derive a count type from a mass type, making beer a suitable argument for the indefinite article. The interpolated-functor model successfully extricates two widely conflated head properties - that of being a syntactic head (determining the distribution of the phrasal projection), and that of being a semantic head-calling for an argument of a particular type (Zwicky 1985, Croft 1996). However, this model also has three significant failings:

- First, it requires a powerful indexing mechanism to constrain coercion operations. Jackendoff (1997:50) notes this issue, pointing out that such operations might "insert arbitrary material into arbitrary arrangements". De Swart (1998:361) seeks to avoid such overgeneration by assuming that a coercion operator is introduced only when there is a trigger for it. For example, a 'unitizing' coercion operator might be indexed to the class of linguistic expressions requiring count-noun sisters, e.g., the indefinite article. However, by enabling a given linguistically expressed operator to invoke a given coercion operator on an 'as needed' basis we do not thereby ensure that that this coercion operator will appear only where needed. For example, there is no obvious means by which to prevent the unitizing operator from intervening between the determiner the and a mass-noun sister (e.g., beer) in the expression the beer - an unwelcome result since this expression need not denote a portion or variety of beer. Coercion operations may be morphosyntactically invisible, but if their representation owes nothing to morphosyntax it is not obvious how they can be constrained. 
- Second, it misses the following generalization: both the 'match' conditions upon which lexical projection is based and the 'mismatch' conditions which trigger implicit type-shifts are created by morphosyntax. On the modular account, there no obvious relationship between strict (projection-based) composition and enriched (coercion-based) composition. The enriched representations do not appear to owe anything to the syntactic configurations in which the particular functor appears. In fact, Jackendoff (1997:50) admits that enriched composition considerably complicates the syntax-semantics interface.

- Third, it cannot account for cases of template-based coercion, as in (3). As noted above, the coercion effects in question cannot be traced to the presence of a specific functor, be it a verb or an argument. Instead, the modulation of meaning is the result of the verb's conformity to a linking pattern whose valence set properly includes that projected by the verb.

- Fourth, it provides no rationale for the existence of type-sensitive operators. What use does an interpretive module have for a set of identity functions? Since functions in construal-based semantic theories are intended to represent cross-domain mappings, type-sensitive operators, whose input and output types are identical, appear to serve no explanatory role.

As an alternative to modular models, I will propose an account of implicit type-shifting based upon the grammatical construction. This account will draw upon the mechanisms and architecture of CONSTRUCTION GRAMMAR (Fillmore et al. to appear, Kay \& Fillmore 1999, Zwicky 1994, Goldberg 1995, Michaelis 1994, Michaelis \& Lambrecht 1996, Koenig 1999). In this model, the grammar is a network of symbolic rules of morphosyntactic combination. As in Bybee's (1995) conception of morphological storage and processing, rules traditionally conceived in processual terms are replaced with schemas which differ from one another with regard to the level of specificity (e.g., whether or not particular words or affixes are invoked) and productivity, as determined both by the restrictiveness of the schema and its type frequency (see Bybee 1995:432). In addition, constructions represent diverse formal objects. Grammatical constructions determine: constituent-structure relations, dependency relations, role-function linkages, linear orderings, and combinations thereof (Zwicky 1994). Grammatical constructions are combined with one another, and with lexical items, via superimposition, a mechanism whose 
technical implementation is UNIFICATION (Fillmore et al. forthcoming, Kay \& Fillmore 1999). Grammatical constructions refer in the same way that words do: they denote types-among them classes of entities and events. Accordingly, coercion is not merely the resolution of semantic conflict, but is instead the resolution of conflict between constructional and lexical denotata. ${ }^{1}$ This interaction is subject to a principle which I will refer to below as the Override Principle. The construction-based model of coercion has the following explanatory features:

- First, it uses a single combinatory mechanism, the construction, to account for both coerced and syntactically transparent interpretations. Rather than representing a special form of composition, coercion effects are predictable by-products of construction-word combination: they mediate conflicts between the meaning of a construction and the meaning of a superimposed lexical item. This means that the constraint which requires semantic concord between the syntactic sisters in the string a bottle also triggers the coerced interpretation found in a beer. Since this concord constraint is stated for a rule of morphosyntactic combination, the same construction underlies both strict and enriched composition.

- Second, it captures head-driven and non-headed (exocentric) coercion effects by means of a single combinatory mechanism. Since combination in unification-based syntax has nothing per se to do with phrase building, licensing is not the unique domain of syntactic heads. Further, since its combinatory mechanisms are based upon schemas rather than sisterhood relations, Construction Grammar provides a straightforward model of 'functor-free' coercion, as exemplified in (3).

- Third, it predicts the existence of two sources of coercion effects: type-selecting constructions (e.g., Indefinite Determination) and type-shifting constructions (e.g., the Progressive). Type-sensitive constructions express concord relations while type-shifting constructions perform derivations. Both kinds of constructions denote types, whether entities or events, and invoke types. When the type provided is not the type invoked, implicit typeshifts may occur. 
The remainder of this paper will be structured as follows. In section 2, I will describe the construction-based model and its unification-based implementation, using nominal syntax to illustrate both transparent and enriched composition. In section 3, I will apply the model to argument structure, drawing upon the framework developed by Goldberg (1995). In section 4, I will analyze three distinct types of aspectual constructions: aspectual concord constructions (as illustrated by the Frame Adverbial construction), aspectual shift constructions (as illustrated by the Progressive), and tense constructions (as illustrated by the Present in English and French).

\section{Coercion by Construction: Nominal Syntax}

Unification of constructions can grossly be described in terms of a metaphor involving the superimposition of slides. A lexical entry can be superimposed upon a construction (or vice versa) as long as the semantic and syntactic specifications on each slide "show through" - that is, provided there is no conflict among the specifications on the slides in the stack. The specifications take the form of attribute-value matrices: a list of syntactic (syn) and semantic (sem) attributes (both relational and intrinsic) with exactly one value assigned to each (including the value [ ], or unspecified). ${ }^{2}$ Among the values of the sem attribute are the attributes INDEX and FRAME. The value of the index attribute is the referential index of the expression. The value of the frame attribute is the set of relations and participant roles which jointly define the type of the expression. The constructions themselves are represented as box diagrams. Each box corresponds to a node in a tree-structure representation, and contains an attribute-value matrix. In a branching construction, a lexical entry unifies with a single daughter box within the construction. The topmost attribute-value matrix of the construction represents the external syntax and semantics of the construction - that is, what instances of this construction 'count as'. The traditional conception of a lexical head-as the determinant of the syntactic category and semantic type of its projection-plays a limited role in this model, as a default. ${ }^{3}$

Unification is used to represent a semantic dependency between two or more types which figure in the statement of a construction. When there is a concord requirement within a branching construction, the two daughter boxes will contain identical atomic values for the relevant attributes. When a range of values is possible, a concord requirement will be indicated by a unification variable, a numbered pound sign \# preceding the empty brackets, e.g., \#1. For example, each of the two daughter constituents in the Determination construction (the article and 
the nominal head) carries the attribute-value pair plural \#[ ] (Fillmore et al. to appear: ch. 2). This concord requirement rules out such tokens as *these person and *this persons. Functorargument relations are represented by the VALENCE attribute. The value of the valence attribute is the set of arguments which a lexical daughter (or its projection) requires, with intrinsic and relational information given for each member of the valence set. An argument of a functor (e.g., a verb) is represented as the daughter which unifies semantically with a member of the valence set of its sister, the functor. While some implementations of unification-based Construction Grammar, e.g., Kay \& Fillmore 1999 (as described in fn. 1), equate any failure of unification with ill formedness, I assume a coercion mechanism whereby constructional requirements (e.g., semantic constraints upon the head daughter) 'win out' over lexical features when the lexical item and the construction upon which it is superimposed have different values for a given attribute. This accommodation mechanism is described in (5) as the Override Principle:

(5) The Override Principle. If a lexical item is semantically incompatible with its syntactic context, the meaning of the lexical item conforms to the meaning of the structure in which it is embedded.

Under (5), coercion is a side effect of the ordinary semiotic function of grammatical markers rather than a special form of composition. Further, (5) targets a broader array of phenomena than do models based on the interpolation of coercion operators. Notice that the Override Principle refers to semantic incompatibility between a lexical item and its syntactic context, rather than merely to the lack of conformity between a particular lexical item and a given grammatical formative, e.g., the indefinite article. In construction-based syntax, meaning-bearing grammatical units like the indefinite article and plural suffix are seen as the semantic heads of PARTIALLY LEXICALLY FILLED CONSTRUCTIONS. This means that grammatical formatives are also grammatical constructions, and the Override Principle subsumes the classic cases of coercion. In addition, however, the Override Principle also explains the source of coercion effects which cannot plausibly be represented in terms of functor-argument relations. One such case is given in (6):

(6) You have apple on your shirt. 
In (6), the word apple denotes a mass type which it would not ordinarily denote. What is the source of that coerced interpretation? There is no determiner or modifier which calls for it. The verbal sister of the nominal, have, cannot be said to coerce the mass interpretation either, since this verb does not select for a mass type. Instead, implicit type-shifting occurs because a verb's object function is filled by a bare nominal. The licensing relationship between a given verb and a nominal which expresses an internal argument of that verb is represented by the Verb Phrase construction, described by Fillmore et al. (to appear: ch. 4). The Verb Phrase construction is both a constituency construction and a dependency construction. It licenses combinations containing a lexical head verb and one or more phrasal complements, whether these complements are arguments or adjuncts. The Verb Phrase label is taken literally: an intransitive verb like disappear, would, in the absence of adjuncts, simply unify directly with the Subject-Predicate construction, as in (7), rather than representing both a lexical verb and a verb phrase, as required by traditional X'-based models:

(7) The problem disappeared.

The Verb Phrase construction represents lexical projection by providing that the valence set of the lexical verb is a subset (potentially a proper subset) of the valence value of the Verb Phrase construction. The Verb Phrase construction requires that all sisters of the head verb represent MAXIMAL categories. ${ }^{4}$ Maximal nouns are those which refer, in the sense of introducing existentially quantified or anaphorically linked variables into semantic representation. Since maximality is a lexical feature, a noun will be marked for one of three maximality values in the lexicon, depending upon lexical class. If a lexical noun is to unify directly with the Verb Phrase construction, it must either bear the lexical feature [+maximal] (as does a pronoun) or have no value for the maximality feature. The only lexical nouns which are unmarked for maximality are those which denote mass types (Fillmore et al. to appear: ch. 2). Via feature co-occurrence restrictions, a negative value for the feature BOUNDED entails an UNSPECIFIED value for maximality. This form of underspecification is used to capture the fact that a mass noun may serve either as a grammatical function via direct unification with one of several constructions which govern the instantiation of verbal arguments, e.g., the Verb Phrase construction, or as a sister in one of several determination constructions, e.g., Definite Determination. What this 
means is that a noun can combine directly with the Verb Phrase construction only if this noun designate an unbounded (mass) type. Since the noun apple designates a bounded type, it must shift its designation in order to unify with the Verb Phrase construction, as in (6). Thus, the mass interpretation in (6) involves the resolution of conflict between the meaning of a word and the meaning of a syntactic pattern. This conflict is resolved in favor of the meaning of the construction, as per the Override Principle. It is the construction, rather than the semantic valency of a particular functor, which instructs the interpreter to construct a mass interpretation for the noun apple in (6).

Any model which extends to 'templatic' or functor-free coercion will a fortiori provide a mechanism for representing those syntactic sisterhood relations which map isomorphically to functor-argument relations. Binary-branching constructions which feature such isomorphic structure provide particularly clear illustrations of both implicit and explicit type-shifting. We will now focus on two such examples drawn from nominal syntax: the Indefinite Determination construction and the Plural construction. In (8-9), we see two pairs of nominal constructs; each pair illustrates one of the two respective constructions. The (a) construct illustrates instantiation of constructional meaning while the (b) construct illustrates implicit type-shifting:

(8) Indefinite Determination

a. She read a book. (lexical match)

b. Did you eat a pudding? (lexical mismatch)

\section{(9) Plural}

a. She bought some pencils. (lexical match)

b. They serve delicious soups. (lexical mismatch)

The Indefinite Determination construction is shown in Figure 1. In this construction, the indefinite article has a valence requirement calling for a noun with specific values for the attributes boundedness, configuration and number. These values are required to match those of the nominal sister. The nominal sister is the syntactic head, but its semantic type is restricted by its sister. The construct $a$ book in (8a) transparently reflects the semantics of the construction: the input lexical item shares semantic feature values with the right daughter of the construction. By 
contrast, the construct a pudding in (8b) illustrates a context of coercion: the noun pudding denotes a mass entity and therefore fails to unify with the construction's right daughter. In accordance with the Override Principle, the relevant feature values of the input noun will switch to those required by the construction. This means that mass nouns like pudding will receive the value $[$ count + ] in combination with the Indefinite Determination construction.

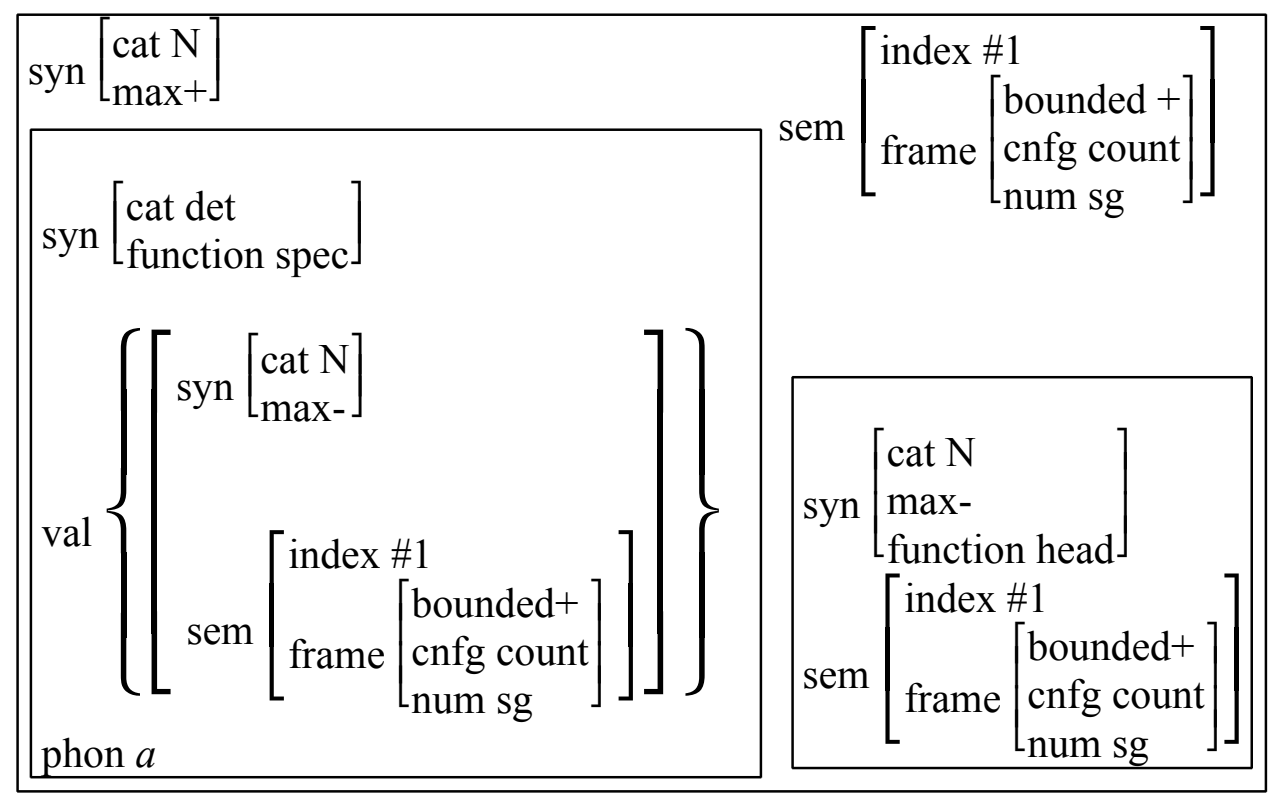

Figure 1. The Indefinite Determination construction 


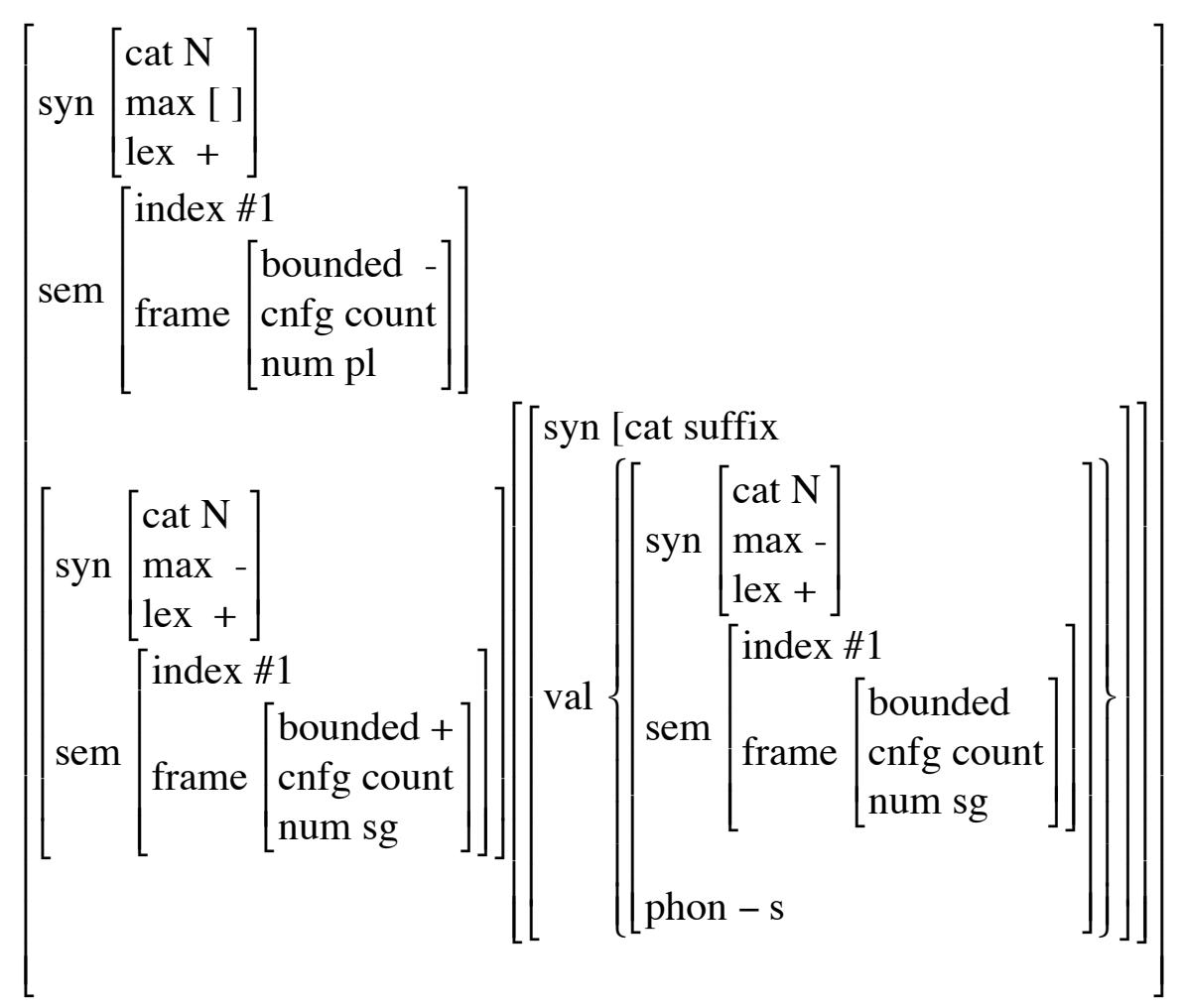

Figure 2. The Plural construction

The Plural construction is shown in Figure 2. Like Indefinite Determination, the Plural construction is binary branching. And like the indefinite article, the plural suffix has a valence requirement which calls for a nominal sister having particular values for the attributes boundedness, configuration and number. The nominal sister shows these same values. Here, the functor's requirements are captured through unification of the semantic features of functor and argument. However, there is no case in which the input lexical item and the construction itself will share all values for the relevant sem features. (By relevant here I mean the set of sem features which excludes the referential index.) The Plural construction SHIFTS the boundedness value of the input noun to [bounded-], producing forms like soups in (9b). Unlike the Indefinite Determination construction, the Plural construction performs two kinds of type shifts - one to which it is dedicated (an explicit type-shift) and one which is a side effect of its dedicated function (an implicit type-shift). Notice that by modeling inflectional morphology as syntactic combination, we potentially incur violations of the principle of lexical integrity, as discussed by Bresnan \& Mchombo 1995. This principle states that elements of morphological structure are not subject to syntactic processes, e.g., recursion. Thus, the Plural suffix cannot be paired with a 
coordinate nominal head, although nothing in the representation in Figure 2 would seem to prevent this. While I leave open the question of how constructions like Plural might be brought into line with lexical integrity, I maintain that inflectional morphology is appropriately represented by constructions, since concord constraints upon sisterhood relations provide a model of coercion effects which exactly parallels that given for syntactic structures like Indefinite Determination. The two kinds of semantic mappings illustrated by (9a-b) are defined in (10-11):

(10) Explicit type-shifting. A shift in the designation of a lexical item (or its projection) by a grammatical construction with which that lexical expression is conventionally combined.

(11) Implicit type-shifting. A shift in the designation of a lexical item (or its projection) in order to reconcile semantic conflict between word and construction, as per (5).

Constructions which inherently perform type shifts differ from those which do not inherently do so. We capture this difference by drawing a distinction between CONCORD CONSTRUCTIONS and SHIFT CONSTRUCTIONS. These two classes are defined in (12-13):

(12) Concord construction. A construction which denotes the same kind of entity or event as the lexical expression with which it is combined. In the case of branching constructions, the construction and its lexical daughter have the same values for the relevant semantic features. Examples: Indefinite Determination, $S M$-determination. ${ }^{5}$

(13) Shift construction. A construction which denotes a different kind of entity or event from the lexical expression with which it is combined. In the case of branching constructions, the construction and its lexical daughter have different values for the relevant semantic features. Examples: Partitive, Plural.

While the Plural is a shift construction, it has something crucial in common with concord constructions like Indefinite Determination: it requires semantic agreement between its two daughters with regard to the boundedness, configuration, and number attributes. When the input noun does not match the semantic feature values requested by the Plural suffix, the result is 
coercion. As per the Override Principle, conflict is resolved in favor of grammatical meaning. Table 1 compares the two types of constructions:

\begin{tabular}{|l|l|l|}
\cline { 2 - 3 } \multicolumn{1}{c|}{} & Implicit type-shifting & Explicit type-shifting \\
\hline Concord constructions & Yes (via (5)) & No \\
\hline Shift constructions & Yes (via (5)) & Yes \\
\hline
\end{tabular}

Table 1. Comparison of the two types of constructions

Table 1 shows that the two types overlap in function, since both types perform implicit typeshifting. Why should this overlap exist? In the case of functor-argument relations, whose constructional analog is syntactic sisterhood, the basis of this overlap is easy to see. Both concord and shift constructions have unification requirements which involve semantic agreement between daughters. Since the Override Principle, as a constraint on conflict resolution, is potentially operative wherever sisters constrain one another semantically, the principle necessarily applies to shift constructions as well.

\section{Argument-Structure Constructions}

Another type of licensing relationship which is mediated by a construction within the Construction Grammar framework is the relationship between a verb and the thematic roles which that verb assigns. The relevant constructions are the argument-structure constructions, as described by Goldberg (1995) and discussed in section 1 above. These constructions are the source of mismatches between the event type denoted by the head verb and the event type denoted by the sentence. An example of such a mismatch is given in (14):

(14) It worked, sir! We bored them right out of the game. (Marcie, Peanuts 10/97)

In (14), the verb bore, which is otherwise a bivalent verb licensing stimulus and experiencer roles, assigns an agent, a theme, and a goal. As a result, the sentence has a construal in which boring people is the means by which they are propelled in a particular direction. Under Goldberg's model, this meaning results from the combination of the verb bore with an argumentstructure construction which denotes causation of a change of state. The valence set licensed by 
this construction properly includes the valence set licensed by the verb. The combination of verb and construction results in augmentation of the verbal valence. It also results in reconstrual of the verb's arguments according to the Semantic Coherence Principle: compatible thematic roles in the respective valence sets contributed by verb and construction are fused; the nonfused thematic roles are those contributed exclusively by the construction (Goldberg 1995: 50-51). Only once we assume that linking patterns denote event types can we speak of such patterns as assigning thematic roles above and beyond those contributed by the verb.

While we have focused on mismatches like (14) in motivating Goldberg's theory, INSTANCES play a crucial role as well. Instances are clauses in which the projection properties of the verb and of the construction are identical. Example (15) illustrates the instance relation between verb and construction:

(15) She put them outside.

The argument structure projected by put is identical to that of the Caused-Motion construction. The fact that instances exist suggests that cases of verb-construction valency mismatch like (14) are appropriately treated as cases of coercion. This in turn suggests the appropriateness of an analogy between argument-structure constructions and functors like the indefinite article-an analogy which Goldberg exploits when she identifies constructions with closed-class expressions (pp. 39-43). The fact that argument-structure patterns create coerced interpretations is relevant for our purposes because it provides further evidence that the Override Principle is best stated in terms of word-construction interactions, rather than functor-argument relations alone. There is no functor that can plausibly be seen as the trigger of coercion in the case of (14). Instead, the modulation of meaning is the result of the verb's conformity to a linking pattern.

Formally, these linking patterns are verb-level constructions which are 'superimposed' upon the lexical entries of verbs. This unification has the effect of augmenting what Fillmore et al. (to appear) refer to as the MINIMAL VALENCE of the verb (the repertoire of semantic roles licensed by the verb). When a verb's lexical entry unifies with one or more linking constructions the result is a FULLY SPECIFIED verbal valence, in which each semantic role of the verb is assigned a grammatical function. Crucially, as we have seen, the theta frame licensed by the 
construction may properly include that licensed by the verb. Figure 3 combines compatible proposals of Fillmore et al. (to appear: ch. 8) and Goldberg (1995: ch. 7):

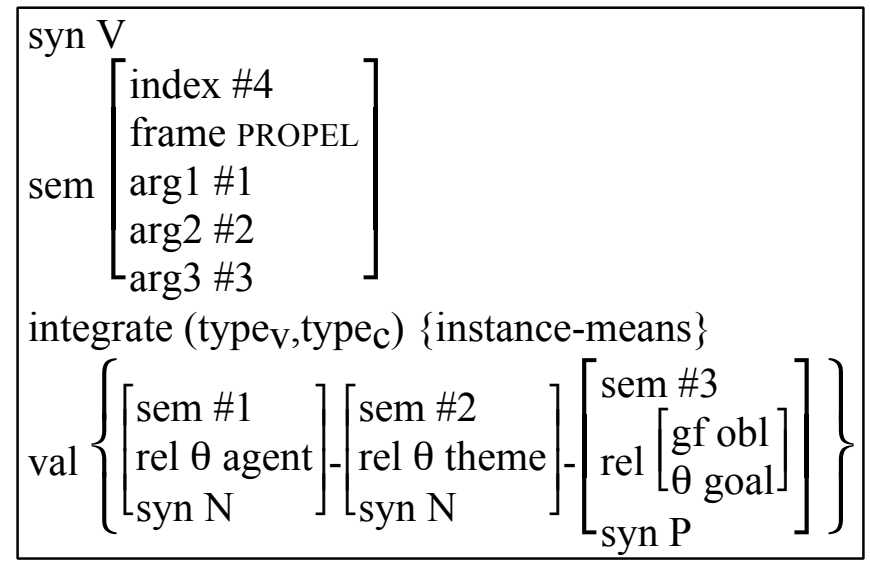

Figure 3. The Caused-Motion construction

As shown in Figure 3, the Caused-Motion construction specifies only one argument linking: the thematic role of goal is linked to an oblique grammatical function. The linking of the remaining arguments depends upon whether this construction unifies with the Passive constuction or the Active construction. These two linking constructions are mutually incompatible. The Passive construction requires that the highest-ranking thematic role be linked to an oblique grammatical function. The Active construction requires that a nondistinguished argument (i.e., non highestranking argument) be linked to the Object grammatical function. In either case, the highestranking unlinked role will receive the Subject grammatical function, which must be assigned to one argument, as per the Subject Principle (Fillmore et al. to appear: ch. 8). What is relevant for our purposes here is the attribute integrate, whose value is the set of verb-construction integration relations licensed by the construction. As described by Goldberg (1995: ch. 7), the Caused-Motion construction permits both instance and means relations. The particular relation selected is determined by the verb itself. As mentioned, verbs which are instances of the construction's semantics, e.g., put in the case of the Caused-Motion construction, license a theta frame identical to that of the construction. Verbs which have a means relation to the construction license a valence set which is properly included by the construction's valence set. This is the case in (14). We view (14) as a case of coercion simply because the Caused-Motion construction, like Indefinite Determination, can and typically does merely exhibit semantic concord with the 
open-class element which combines with it. In (14), concord is 'forced', via the Override Principle, as is the count reading of the noun pudding in the nominal construct a pudding. Concord, or the achievement of concord, involves valence matching in the case of argument structure. This means that we must recognize concord requirements as facts about grammatical patterns, not merely functors. However, while we will view coercion effects through the lens of the constructional framework, we must also keep in mind that many such effects can also be seen as involving the resolution of conflict between the requirements of a given functor and the particular argument with which that functor is paired.

Argument structure also demonstrates the constructional basis of explicit type-shifting. The Way-construction, described in detail by Levin \& Rapoport (1988), Jackendoff (1990), Goldberg (1995) and Israel (1996), inter alia, provides an example of explicit type-shifting involving the augmentation of verbal valency. Examples of this construction are given in (1617), with the coerced verbs shown in boldface:

(16) She talked her way into the shareholders' meeting.

(17) [A]nyone who has ever had the occasion to observe the average American family as they snack their way toward the departure gate[...] (Fran Lebowitz, Vanity Fair 10/97)

The meaning of the Way-construction, as described by the aforementioned authors, involves the motion of an agent creating a path by means of some activity or in a particular manner-in the case of (16-17), talking and snacking, respectively. The construction's head, an intransitive verb, denotes an activity which does not involve directed motion (e.g., neither talking nor snacking involve directed motion). The event denoted by the construction is an act of motion along a path. There is no verb which licenses a theta frame identical to that of the Way-construction. In fact, verbs which $d o$ denote directed motion inherently are not welcomed by the construction:

(18) ??He walked his way into the meeting.

(19) ??She ran her way along the shore.

These facts suggest that the Way-construction is inherently a type-shifting device, since the event type denoted by the construction is always distinct from that denoted by the verb with which the construction combines. Figure 4 gives a representation of the Way-construction which reflects its 
role as a type-shifting device: the set of verb-construction integration relations does not include the instance relation:

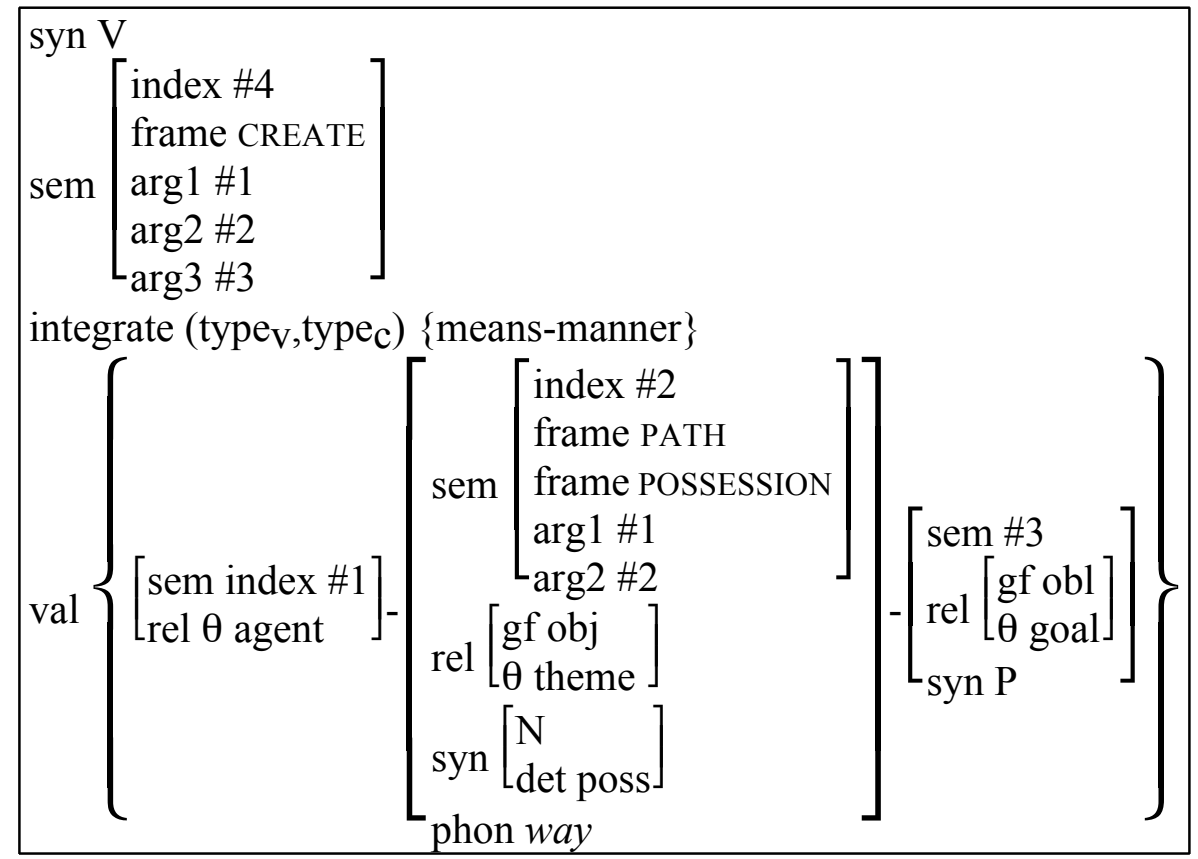

Figure 4. The Way-construction

We will see below that constructions which perform explicit type-shifting can perform this function in a quasi-iconic fashion. These constructions are generally phrasal: the phrase contains a head and a complement denoting distinct semantic types. The head determines the type denoted by the construction. The Progressive construction, as we will see, conforms to this description. However, our examination of the Way-construction has shown that explicit type-shifting via construction does not require the existence of a sisterhood relation. Explicit type-shifting entails only that the construction denotes a type distinct from that denoted by the lexical (open-class) expression with which the construction combines. As a shift construction, the Way-construction imposes aspectual constraints upon input verbs, and, as predicted by the Override Principle, it therefore also triggers coercion effects. Since the verb which combines with the construction is necessarily construed as an activity, verbs which do not otherwise have processual readings receive such readings in the context of the construction. Examples of implicit type-shifting involving the Way-construction are given in (20-21): 
(20) She blinked her way into the light.

(21) He dove his way into the hearts of millions of viewers (??with a single dive).

While blink and dive have momentaneous (semelfactive or achievement) readings under ordinary circumstances, they are interpreted as iterated events in the context of the Way-construction: the subject-denotatum in (20) is necessarily construed as having blinked numerous times; the subject-denotatum in (21) is necessarily understood as having performed a series of dives. Such iterated events, or event chains, qualify as activities, as I will argue in section 4.1 below. Since the construction requires that the input verb denote the means or manner of directed motion, rather than directed motion itself, verbs which inherently denote directed motion are not welcomed (see (18-19)). However, as Goldberg observes (1995:205), verbs of directed motion are permitted in contexts in which "a basic-level motion verb is understood to imply motion despite difficulty":

(22) The novice skier walked her way down the ski slope. (=Goldberg's (22a))

The explanation which I offer for the relative felicity of (22) is compatible with Goldberg's, but requires a further assumption about the construal of walk: it does not denote a verb of directed motion. In essence, the Way-construction is here stripping the verb walk of its directed-motion component, so that the addition of the directed-motion component by the CONSTRUCTION makes sense. We will see this same combination of semantic theft and reimbursement in the case of Progressive-form statives. Notice, however, that the coercion effects found in (20-22) do not arise from an agreement requirement holding between two sisters. The requirement common to all shift constructions, branching and nonbranching, is that the open-class expression must provide the input type that the shift requires. If the open-class form does not denote a type appropriate to the shift, coercion occurs. As per the Override Principle, coercion is asymmetric: only the input type (the lexical expression), and not the output type (the construction's denotatum), is changed in the resolution of a type mismatch. 


\section{Aspectual Constructions}

4.1. Aspectual meaning. The semantics of aspectual constructions are complex, but a good deal of the confusion surrounding aspectual meaning appears to have arisen from the failure of many theorists to distinguish between the CODING of aspectual categories, as by verbs, and the INVOCATION of aspectual categories, as by constructions. For example, the perfective and imperfective Past constructions of Romance are frequently referred to as exponents of 'grammatical aspect' when in fact, as De Swart (1998) and others have argued, such constructions are actually aspectually sensitive TENSE operators. Once coding and invocation functions are distinguished, the rationale for a division between grammatical and lexical aspect (Aktionsart) becomes less apparent. According to this traditional division, verbs and verbal projections express ontological distinctions, e.g., the event-state distinction, while grammatical markers express viewpoint-based distinctions, e.g., the perfective-imperfective distinction. For example, Smith (1997:73) analyzes imperfective marking as the means by which a speaker "presents part of a situation, with no information about its endpoints". This type of account is intuitive in that it based upon a visual metaphor: the grammatical aspects are lenses of various powers through which speakers view the event schemas denoted by verbs. It is difficult, however, to extend this model to other conceptual domains. If we were to say, for example, that the speaker who pairs a mass noun with an indefinite article is 'attending to the boundaries of the substance', we would miss a generalization: this speaker is presenting a mass as an individuated entity by using the syntactic structure otherwise projected by count nouns. By the same token, the speaker who combines a state verb with the morphosyntax typically projected by an event verb is presenting that state as an instance of the event category. If aspectual encoding is a form of categorization, it is reasonable to conclude that the ontological distinctions which figure in Aktionsart-based categorization underlie semantic representation at both the lexical and constructional levels. Constructions, as we have seen, both denote and evoke event types. The invoked event type may or may not be identical to the type denoted by the invoking construction. Invoked and denoted event types are identical in the case of concord constructions and distinct in the case of shift constructions. While only constructions evoke, both words and constructions denote. Therefore it stands to reason that aspectual meaning, whether expressed by a construction or a verb, should be represented in the same way. 
If Aktionsart classification is to provide a unified aspectual semantics, than it must provide an inventory of types sufficient to describe all of the mappings involved in explicit and implicit aspectual type shifts. This system of representation must capture the fact that, for example, activities pattern with states for some grammatical purposes and with telic events for others. Thus, the inventory of Aktionsart types must be hierarchically organized. The primary ontological division in this hierarchy has an epistemological basis: states are those situations whose existence can be verified on the basis of a momentaneous 'sample', while event verification requires tracking over time. Let us illustrate this criterion by application to the least prototypical class of events - activities. As described by Langacker (1987, 1991), activities are those situations which either involve repeated type-identical subevents (heterogeneous activities) or are conventionally construed as episodes (homogeneous activities). Verification of a heterogeneous activity, e.g., running, requires several frames. Since running consists of successive leaps involving alternating legs, witnessing a single leap is insufficient to verify an event of running. Verification of a homogeneous activity, e.g., holding a broom, standing in a corner or sleeping, requires access to points of inception and termination, as well as several contiguous frames between those endpoints. Sleeping is distinct both from being comatose and from nodding off for a second, and staying at one's sister's house is distinct both from popping in on one's sister and living with her. While states like being tall endure in the same way that the events of sleeping and standing in a corner do, states do not take time: any subinterval of a state counts as an instance of that same state. The existence of a state can thus be confirmed on the basis of an atemporal sample. The same cannot be said of a STATE PHASE. ${ }^{6}$ Examples of statephase predications are given in $(23 a-b)$ :

(23) a. She was sick for three days.

b. She was short as a child

Once the duration of a state is fixed, as in (23a-b), it is 'tracked' in the same manner that an activity would be. Unlike activities, however, state phases do not entail energy input. For example, one can try to sleep or lie on the floor, but one cannot try to be sick for three days or to be short as a child.

The epistemic criterion described here is highly compatible with the picture of the eventstate distinction which emerges in the viewpoint-based models of grammatical aspect discussed 
above: perfective aspect involves 'endpoint focus' because the assertion that an event exists entails confirmation that this event has begun or ceased, or both. Under the assumption that grammatical aspect and Aktionsart have uniform semantic representations, we expect that categories at the two levels will have such isomorphic characterizations. Figure 5 gives a hierarchical representation of the Aktionsart classes:

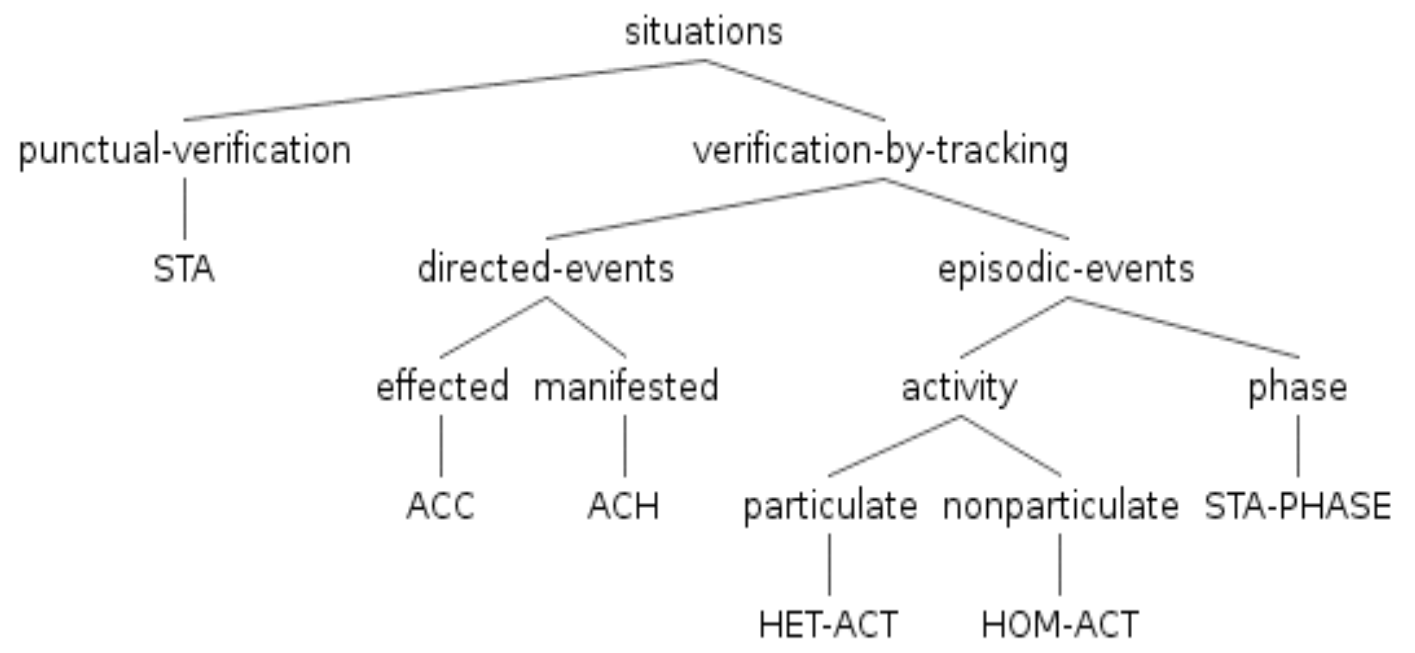

Figure 5. Hierarchical structure for the Aktionsart classes

In Figure 5, situations are divided into those which take place over time (events) and those which hold at a given point in time, states (STA). Within the class of events, a division is made between those events which culminate in a specific resultant state (directed events) and those which do not (episodic events). The class of directed events is divided into accomplishments (ACH), effected changes of state, which involve a preparatory process, and achievements (ACH) Achievements are state changes which come about rather than being brought about (Dowty 1986, Van Valin \& LaPolla 1997). Within the class of episodic events, we distinguish between activities and phases. The label activity is used to refer to the class of actions which occur over a period of time but do not culminate (Binnick 1991:142-143). This category includes both internally homogeneous activities (HOM-ACT) and activities which comprise iterated subevents (HET-ACT). The category of phase includes nondynamic situations which nonetheless have duration. This category has a single member, that of state phases (STA-PHA). Because state phases begin and end within the reference interval, they can be assigned an explicit duration, as in (23a). In contrast to states, state phases have perfective behavioral properties. For example, they can be 
enumerated, as shown in (24a), and they cannot be reported by means of the simple Present tense, as shown in (24b). Like states, however, state phases require no energy expenditure for their maintenance:

(24) a. Anna was ill for two weeks twice

b. *Anna is ill for two hours.

Situation types are both conceptual gestalts and topological structures. Aspectual topology underlies space-time analogies that are widely used in aspectual theory, in which states count as masses and events as individuals based on criteria like enumerability and internal composition (Mourelatos 1978). Gestalt-based situation-type categorizations describe the relationship of the situation type in question to a causative prototype (Smith 1997, Croft 1998). They are fundamental to aspectually based theories of argument linking. It therefore makes sense that both causal and temporal representations matter in aspectual type shifts. In the next three subsections, I will describe these two representational systems and two mapping operations, permutation and concatenation, which mediate between input and output representations .

4.1.1. Causal representation. Rappaport Hovav \& Levin (1998), henceforth RHL, capture the distinction between aspectual and frame-specific features of verb meaning by proposing a set of fixed event-structure templates with which verbs can combine. Verbs 'fill in' information represented by constants; the type of the constant determines the information that the verb must provide. Table 2 presents an adaptation of RHL's inventory of event-structure templates. 


\begin{tabular}{|l|l|}
\hline Aktionsart Class & Causal Representation \\
\hline State & {$[\mathrm{x}<$ STATE $>]$ e.g., seem } \\
\hline State phase & {$[$ HOLD $[\mathrm{x}<$ STATE $>]]$ e.g., be sick for two days } \\
\hline Homogeneous activity & {$[\mathrm{x}$ HOLD $[\mathrm{x}<$ STATE $>]]$ e.g., sleep } \\
\hline Heterogeneous activity & {$[\mathrm{x}$ REPEAT $[\mathrm{x}<$ EVENT $>]]$ e.g., skip } \\
\hline Achievement & {$[$ BECOME $[\mathrm{x}<$ STATE $>]]$ e.g., sink } \\
\hline Accomplishment & $\begin{array}{l}{[[[\mathrm{x} \text { REPEAT }[\mathrm{x}<\text { EVENT }>]] \text { CAUSE }[\text { BECOME }[\mathrm{y}<\text { STATE }>]]] \text { e.g., }} \\
\text { build }\end{array}$ \\
\hline
\end{tabular}

Table 2. Causal representation (based on Rappaport Hovav \& Levin 1998)

In these templates, operators (shown in small caps) represent subevent connectives in the Jackendoff-Dowty-Vendler tradition, while variables represent participant roles. Constants are represented by the italicized material in angled brackets. I have augmented the RHL inventory of event templates in order to represent Aktionsart classes and event properties which, while having no direct relevance to verbal argument structure, figure prominently in aspectual type-shifts. The class of state phases has been added and the class of processes split into two classes: homogeneous and heterogeneous activities. The state-phase template, as shown, contains the operator HOLD. This operator combines with a stative situation type to yield a state which begins and ends within the reference interval. The homogeneous-activity template, as shown, also contains the operator HOLD. In this template, however, HOLD takes two arguments: a state radical and an effector. The effector argument is also an argument of the state radical; this notation reflects the fact that the subject-denotatum, although nonagentive, is responsible for the maintenance of the denoted state. The template for heterogeneous activities contains the operator REPEAT. This operator has the same valence and 'control' properties which HOLD has in the homogeneous-activity template. The use of the REPEAT operator captures the observation that heterogeneous activities, e.g., skip, consist of iterated type-identical events. Since a heterogeneous activity is itself an event, a heterogeneous activity may replace the event variable in the heterogeneous-activity template. The resulting event is an event chain, or, equivalently, a heterogeneous activity. As in RHL's original model, the achievement template properly includes the state template, while the accomplishment template contains the templates for activities, achievements and states, respectively. 
RHL propose a single mechanism of semantic derivation, TEMPLATE AUGMENTATION: "Event structure templates may be freely augmented up to other possible templates in the basic inventory of event structure templates" (p. 111). The added structures are the subevents represented by operators, e.g., BECOME. Template augmentation involves the unification of Aktionsart representations. Through template augmentation, an event-structure template, e.g., the heterogeneous-activity template, projects that event-structure representation by which it is entailed - the accomplishment template. Template augmentation thereby drives verbal valence augmentation at the syntactic level. For example, the verb sweep has both a monovalent activity pattern (She swept for hours) and a trivalent accomplishment pattern, in which it denotes causation of motion (She swept the dust off the steps); the accomplishment template licenses both the direct object and locative oblique.

Template augmentation is a more constrained operation than unification, in two respects. First, augmentation allows only pairwise unifications. Second, augmentation is limited to the addition of a single subevent, as expressed by an operator and the arguments it projects. For example, although accomplishment and state templates overlap, creating an accomplishment template from a state template would entail the addition of two subevents: that headed by BECOME and that headed by CAUSE. One can, however, build an accomplishment representation from an activity representation: this entails the addition of a single subevent, represented by the operator CAUSE and its two situation-type arguments, an activity radical and an achievement radical. The first argument unifies with the representation of the input type. As we will see, both of these constraints can be violated by aspectual mappings.

4.1.2. Temporal representation. Temporal representation captures the patterns of stasis and change which characterize each situation type. They do not, for example, represent causal links between contiguous situations or agentive implications attaching to certain participants. Table 3 gives temporal representations for the six Aktionsart classes discussed above: 


\begin{tabular}{|l|l|}
\hline Aktionsart Class & Temporal Representation \\
\hline State & $\phi$ \\
\hline State phase & $\tau \phi \tau$ \\
\hline Homogeneous activity & $\tau \phi \tau$ \\
\hline Heterogeneous activity & \multicolumn{1}{|c|}{$\tau \phi[\tau \phi] \tau$} \\
\hline Achievement & \multicolumn{1}{|c|}{$\tau \phi$} \\
\hline Accomplishment & $\kappa \tau \phi$ \\
\hline
\end{tabular}

Table 3. Temporal representation (based on Bickel 1997)

These representations utilize three situation-type components: STATES $(\phi)$, TRANSITIONS $(\tau)$, and EVENT CHAINS (к). States are internally homogeneous situations which include no transitions (i.e., temporal boundaries). For this reason, we say that states INCLUDE the intervals at which they hold (Partee 1984, Herweg 1991). Transitions are state-change events, and as such are isomorphic to achievements. However, the category of transitions is not limited to those inchoative events which are lexicalized as achievement verbs, since it also includes the events of INCEPTION and CESSATION, which jointly define the endpoints of a situation. For example, the endpoints of sleeping, a homogeneous activity, are, respectively, the events of falling asleep and waking up. Unlike states, transitions cannot stand alone, nor can they be iterated without the mediation of a state. Accordingly, the representations $*[\tau]$ and $*[\tau \tau]$ are ill formed (Bickel 1997:126). By contrast, the representation $[\tau \phi \tau]$ is well formed; it corresponds to both a state phase and a homogeneous activity (recall that agentive properties are invisible to temporal representation). When the representation $[\tau \phi \tau]$ is iterated it corresponds to an event chain or heterogeneous activity $(\kappa)$. The representation corresponding to heterogeneous activities contains the notation $[\tau \phi]^{+}$, denoting one or more instances of particular state change, e.g., that of crossing from one side of the room to another in an event of pacing. While both heterogeneous activities and homogeneous activities can be protracted indefinitely, the mechanisms are different in each case. In the former case, expansion entails iteration, while in the latter case expansion simply entails lack of change. Notice, however, that in neither case does expansion have any effect upon bounding: the initial and final transitions are present whatever intervenes between them. When a heterogeneous activity is embedded in an accomplishment representation, 
shown in Table 2 as [ $\kappa \phi$ ], its offset transition is superimposed upon the initial transition of the embedded achievement, $[\tau \phi]$. This reflects the observation that, for example, in an event of walking home, the threshold-crossing transition is also the final step of the walk.

The constraint which rules out sequences of the form $*[\tau]$ and $*[\tau \tau]$ need not be stipulated, since one cannot logically conceive of an inchoative event which is unaccompanied by a resultant state. Notice, however, that in the temporal representations given in Table 2 resultant states are not consistently indicated. In particular, states which follow events of termination are missing from the representations. These states are not indicated because they can be 'read in' on the assumption that transitions are isomorphic to achievements. Notice, however, that ANTECEDENT states are equally crucial to the definition of transition, and our temporal representations lack these as well. Let us assume, therefore, that antecedent states and consequent states - as well as periods of stasis which lie BETWEEN chained events - can be subsumed under the rubric of RESTS. The term rest is meant to be construed as it is in rhythmic representation: a pause between 'beats', or transitions. While in the foregoing remarks I have distinguished intermediate states from antecedent and consequent states, this distinction is not particularly meaningful: because events are located with respect to one another on a time line, all events potentially qualify as chained events and all states can be construed as intermediate states. This point will become particularly relevant when we consider chained events which represent habitual and generic situations.

4.1.3. Aspectual mapping. Rather than being suppletive relations, aspectual mappings are based on shared structure. That is, all aspectual mappings are subject to a principle which I will refer to as Aktionsart Preservation. This principle is described in (25):

(25) Aktionsart Preservation. In an aspectual mapping, whether implicit or explicit, input and output types must share some portion of their respective causal and/or temporal representations.

Aktionsart Preservation governs two kinds of operations upon Aktionsart structure: PERMUTATION and CONCATENATION. Permutation operations add or select a single component of the input Aktionsart representation. The definition of component differs according to whether we are using causal or temporal representation. In causal representation, a component corresponds to 
an operator, e.g., HOLD, and the arguments it projects. In temporal representation, a component corresponds to a state, transition or event chain. As an example of addition, consider the transition from state to achievement. This type shift occurs implicitly when, for example, a frame adverbial is combined with a state radical, as in (4a), repeated here as (26):

(26) She liked him in a minute.

This type shift involves the addition of the operator BECOME, or, equivalently, a transition, to the causal or temporal representation of the state. ${ }^{7}$ As an example of selection consider the explicit type shift performed by the copular resultative construction in English:

(27) a. The truck is loaded.

b. The soup is cooled.

The resultant-state predications in $(27 \mathrm{a}-\mathrm{b})$ denote states, or more specifically those states which are embedded in the Aktionsart representations of their participial complements. These states are, respectively, that of the truck being full and that of the soup being cool. The stative type shift performed by the resultative construction involves selection of the state component in the causal or temporal representation of the lexical verb. Since both the accomplishment verb load and the achievement verb cool entail a resultant state, the application of selection conforms to Aktionsart Preservation. Notice, however, that the type shift exemplified in (27a) is not incremental: states and accomplishments differ by more than a single component of Aktionsart representation, since the accomplishment entails two subevents (an activity and an achievement) which the state does not.

Occasionally, permutation operations appear to violate Aktionsart Preservation These violations are in fact only apparent, since the relevant mappings are in fact mapping chainsordered pairs of mappings, the first of which feeds the second. I will refer to these chained mappings as INDIRECT TYPE SHIFTS since they involve the mediation of a third aspectual category. Indirect type shifts exist because semantic transitions, as equivalence relations, are transitive; that is, if $\mathrm{A}=\mathrm{B}$ and $\mathrm{B}=\mathrm{C}$ then it follows that $\mathrm{A}=\mathrm{C}$. Indirect type shifting will be invoked below in the analysis of the Progressive. 
2.4.3. Concatenation. Like other mappings in the general class of repetition operations, concatenation applies to an event type (i.e., dynamic situation radicals), and outputs a series of events which are type identical both to one another and to the input event. In addition, like other iteration operations, concatenation is used to represent both implicit and explicit type shifting, e.g., coerced readings triggered by frequency adverbials, as in (28):

(28) She was depressed several times last year.

The difference between concatenation and its predecessor notions lies in the nature of the output type. While repetition operations are typically assumed to output state types, concatenation instead outputs an event chain, which, as discussed above, qualifies as a heterogeneous activity rather than a state. The identification of event chains with heterogeneous activities is an independently motivated one, since, as has been widely observed, telic verbs with multiplex complement denotata receive activity readings. Note, for example, the contrast between the sentence She ate mushrooms, which asserts an activity, and the sentence She ate a mushroom, which asserts an accomplishment. Further, as Smith observes (1997:51), the syntactic properties of habitual predications suggest that they are event predications: they can appear in imperatives, with agent-oriented adverbials like deliberately, and in pseudo-cleft constructions. The syntactic constructions in question do not in general appear capable of coercing perfective readings of stative predications: sentences like (29a-b) are awkward at best:

(29) a. ??What she did was prefer white wine

b. ??Prefer white wine!

Finally, by rejecting the assumption that repeated events are ipso facto stative, we resolve a longstanding paradox in the literature on generic aspect: situations which consist of multiple type-identical subevents, e.g., pacing, qualify as events rather than states; it is not obvious therefore why event radicals which otherwise qualify as unique events receive coerced repeatedevent interpretations in morphosyntactic contexts which call for state radicals. Two such contexts are illustrated in (30):

(30) a. She smokes. 


\section{b. She smoked when I met her.}

Habitual sentences appear to be recognized as such only on the basis of a mismatch between eventive verbal Aktionsart and the syntactic context in which that verb appears. For example, Bybee, Perkins \& Pagliuca (1994), in attempting to motivate a grammatical category of present habitual sentences, observe that "the difference between habitual and present stative resides entirely in the lexical meaning of the predicate: the present habitual reading of dynamic predicates covers many different instances of the same situation, while the present stative covers one continuous situation" (p. 152). It therefore appears appropriate to conclude that habitual meaning is a specific type of coercion effect, achieved by combining an event-chain radical with a state-sensitive construction. I therefore propose to treat habitual-event radicals and iteratedevent radicals as indistinguishable at the level of Aktionsart structure: both qualify as heterogeneous activities. Accordingly, the concatenation operation takes us only part of the way toward a stative interpretation; it yields a heterogeneous activity. It is at this juncture that perfective and habitual meanings are compatible. The permutation operation of selection provides the ultimate bridge to stative meaning: since iterated events contain intermediate rests, and since such rests qualify as states, those type shifts which require stative input types (whether implicit or explicit) are free to select intermediate rests. In the next two sections, we will use the two Aktionsart-based operations of permutation and concatenation to analyze the type shifts performed by aspectual shift constructions and aspectual concord constructions.

4.2. Aspectual concord constructions: The Frame Adverbial construction. The Frame Adverbial construction is represented in Figure 6. This construction is an adjunct-licensing construction as described by Kay \& Fillmore (1999:11-12). Adjuncts and arguments are licensed in distinct ways in this model. While arguments are valence elements of the minimal lexical verb, adjuncts are contributed by particular constructions which unify with a lexical verb entry, augmenting the verbal valence. The result is a verb entry, rather than a branching structure. This flat representation appears justified in light of the fact that there is no strong evidence for the recursive branching V' structures that have traditionally been used in X-bar models to represent strings of adjuncts. In Figure 6, we see that the Frame Adverbial construction adds an adverbial expression to the valence set of the lexical verb. This valence set minimally contains one 
additional valence member, that element whose grammatical function is subject. The adverbial element (a preposition phrase headed by in) itself has a valence structure. The first member of the valence set is an event expression, whose semantic index is identical to that of the verb itself. The second valence member is an oblique expression denoting an interval. The semantic frame expressed by the adjunct is one in which event occurrences are counted. This construction is a concord construction. The construction denotes a telic event and the valence set of the adverbial element calls for an event of this same type. This construction is unlike Indefinite Determination, in that it is nonbranching: there are no boxes within it. Nonetheless, this construction projects a sisterhood relation and constrains this relation by means of an aspectual concord requirement, making it analogous to constructions like Indefinite Determination.

The adjunct which is added to the verbal valence is interpreted according to the logic of containment, as described in section 1. As discussed in that section, judgements of containment entail upward vis-à-vis intervals, and are therefore limited to those events which culminate within the relevant time frame. Therefore, frame adverbials select exclusively for those event radicals which denote or entail a change of state. As a result, examples like (31) represent contexts of coercion:

(31) My radio program ran in less than four minutes.

De Swart observes (1998:359) that examples like (31) allow both achievement and accomplishment readings. In (31), the frame adverbial in less than four minutes either denotes the running time of the program or the time during which the program began to air following some other event (say, a call to the radio station). These two readings involve distinct permutations of the input activity representation. Addition of an inchoative event to the causal structure of the input activity yields the accomplishment reading. The achievement reading, by contrast, results from selection: the event selected is the onset phase $\tau$ in the temporal representation of the input activity. The semantic representation of the construction is captured by the semantic frame labeled WITHIN. This frame has two arguments: a telic event and an interval. These arguments are coindexed with linguistic expressions listed in the valence set of the preposition in. As a concord construction, the Frame Adverbial construction licenses instances, as in (32): 
(32) She fixed the problem in a few minutes.

In (32), the verb matches the type called for by the valence of the frame adverbial: the class of telic (or, equivalently) directed events. ${ }^{8}$ Via the Override Principle, this construction also performs implicit type-shifting, as in (26): She liked him in a minute. In this example, a stative verb receives an inchoative construal: the event denoted is the onset of the liking state and therefore counts as an achievement. This construal involves the addition of the inchoative operator BECOME to the Aktionsart representation of the state; it reflects the reconciliation of a unification conflict between the verbal Aktionsart and the constructional semantics as per the Override Principle.

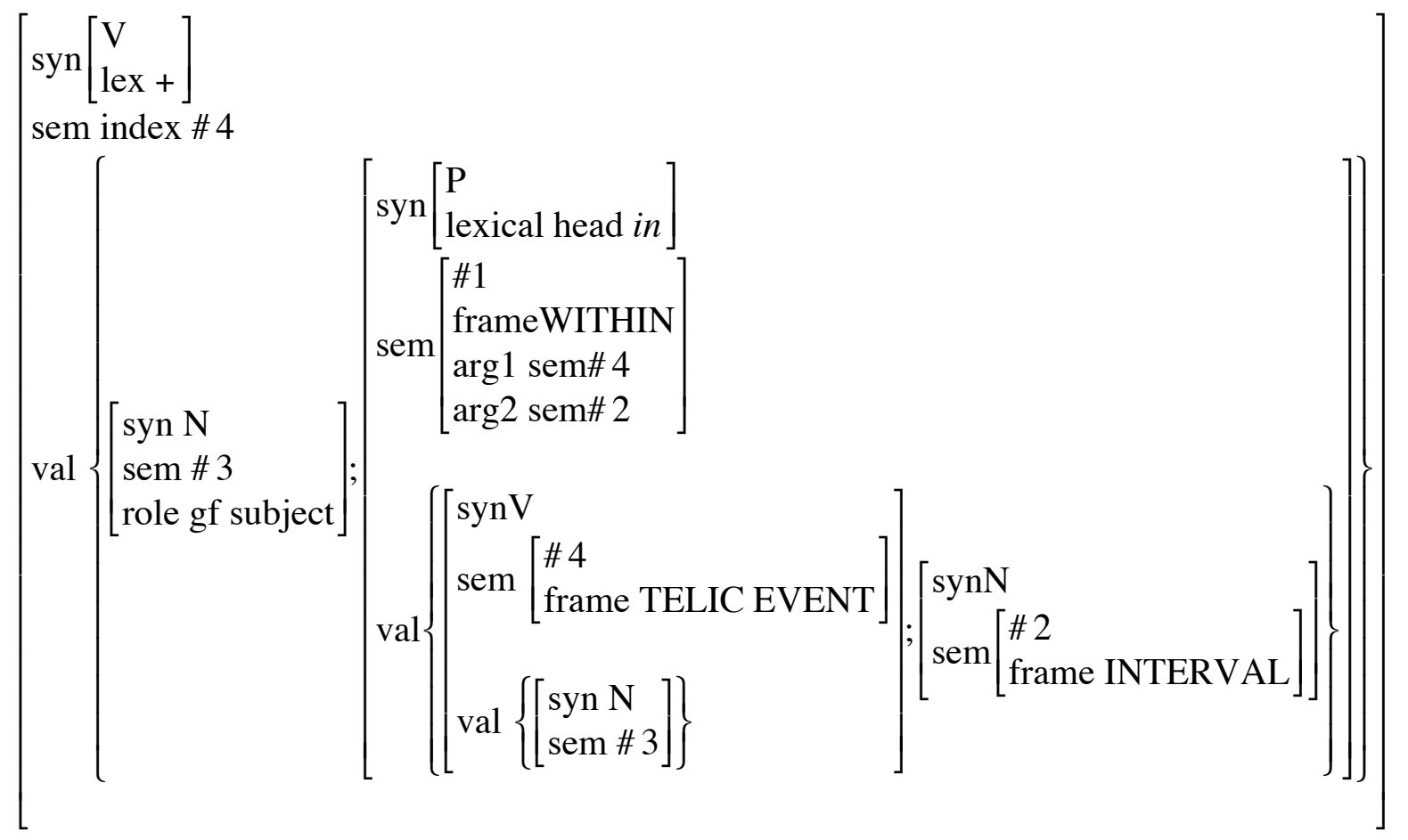

Figure 6. The Frame Adverbial construction (concord)

\subsection{Aspectual Shift Constructions: The Progressive}

The Progressive, like the Frame Adverbial construction, specifies a concord relationship via cross-indexation in paired valence sets. Unlike the Frame Adverbial construction, however, the Progressive construction also contains information about constituent structure: it has a binary- 
branching structure, in which an auxiliary head (be) is paired with a VP sister whose morphology is that of a gerund. The aspectual mapping performed by the Progressive is directly reflected in its formal structure: the auxiliary head denotes a state and the participial complement denotes the situation radical from which that state is derived. However, a precise aspectual characterization of the type denoted by the complement has proven elusive. The Progressive appears to be less selective with regard to its input type than its type-shifting function would lead one to predict. I will argue that this apparent lack of selectivity in fact reflects restrictive input conditions coupled with broad coercive capacity.

The Progressive construction is shown in Figure 7. It is an instance of the Coinstantiation construction, as described by Kay \& Fillmore (1999:22-23). The Coinstantiation construction captures both raising and control phenomena by requiring unification of the INTRINSIC (nonrelational) semantic values of an argument of the head verb and that valence member of the VP complement whose grammatical function is subject. In Figure 7, the unification formula captures the 'raising' property of the auxiliary head be. The Progressive as depicted in Figure 7 is a shift construction: its VP complement denotes an event of the ACTIVITY Aktionsart type ${ }^{9}$ and the construction denotes a state which holds during the interval for which the activity goes on (this period is represented as an argument of the ACTIVITY frame, where it carries the referential index \#5). The explicit type-shift performed by the Progressive involves the selection operation: the state which the Progressive denotes represents an intermediate rest in the temporal representation of the input activity. 


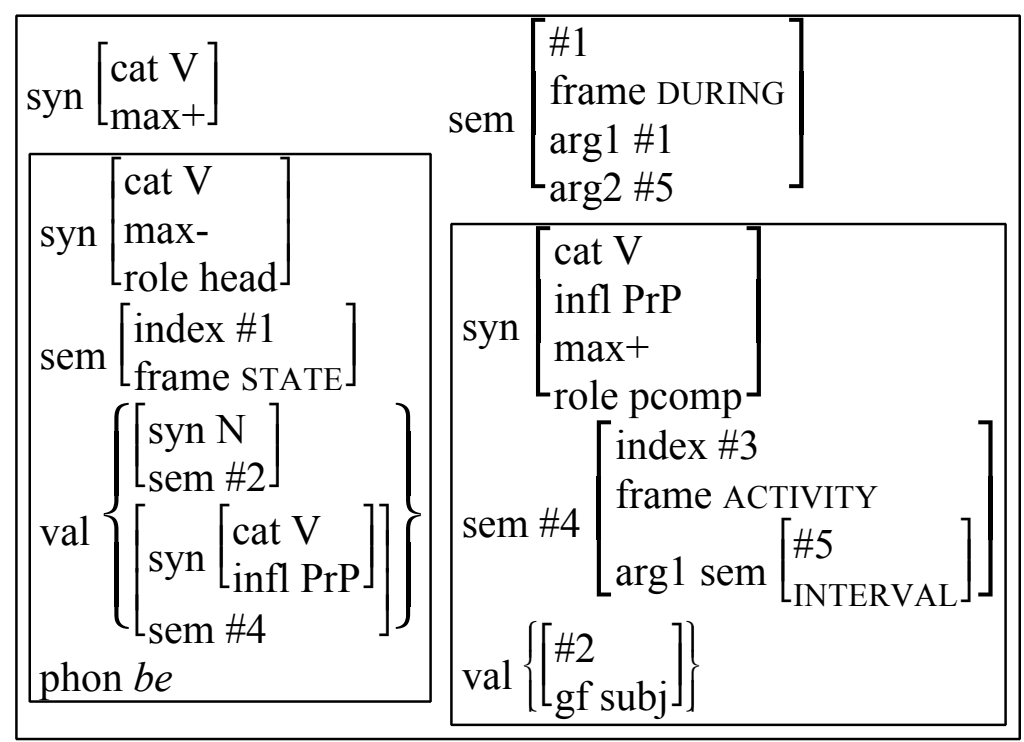

Figure 7. The Progressive construction (shift)

The Progressive construction can unify with any tense construction. A sentence which is licensed by the combination of the Progressive construction and a tense construction (e.g., the Past) has an interpretation which is identical to that of a simplex state predication of the same tense. As per Partee (1984), we assume that states include the reference time for which they are asserted. This inclusion relation accounts for the ability of a state to temporally overlap prior and subsequent events in a temporal discourse. Events, by contrast, are included within the reference times for which they are asserted, accounting for our intuition that events succeed one another in a temporal discourse.

The Progressive, as a stativizing device, triggers coercion when combined with a stative complement VP, as per the Override Principle (5). The concord feature which is relevant to the application of the Override Principle is the feature ACTIVITY, which, as required, is invoked by both daughters in the construction. This feature expresses the semantic type of the VP complement and, via the unification index \#4, the semantic value of the second valence member of the auxiliary head be. The activity feature 'wins out' over the stative feature of the input lexical item. By analyzing the VP complement of the Progressive construction as denoting an activity, we capture the intuition that Progressive-form state predications like (4b) I'm living on Pearl Street, as well as those in (33-35) below, express 'temporary states': 
(34) He is remaining stable.

(35) Right now she's believing there's going to be a reconciliation.

The 'temporary states' expressed by (4b) and (33-35) are not in fact states but homogeneous activities. To see this, recall the basis upon which we analyzed certain apparently stative verbs, e.g., sleep, hold one's breath, as denoting activities: such verbs exhibit perfective behaviors. For example, Present predications containing these verbs cannot be used to report upon events ongoing at speech time. This is shown by (36-39), where the \# indicates infelicity on a reportive reading, rather than, e.g., a habitual one:

(36) She's the one in the corner. \#She wears a Fendi blazer.

(37) Try to be quiet! \#The baby sleeps!

(38) \#He holds his breath.

(39) \#Your socks lie on the floor.

Activities, like accomplishments, are enabled to continue by the energy input of an animate entity. The subject denotata of such predications are participants in a causal chain, whether they are agents, effectors or objects which an agent has oriented or configured in a specific way (e.g., socks which are in a bundle are located on the floor but not lying on the floor). The complement VPs in Progressive sentences like We were living in Boulder denote internally homogeneous activities analogous to those which require the Progressive form in (36-39). ${ }^{10}$ The effector argument assigned by the operator HOLD in the causal representation of the homogeneousactivity type represents the agentive properties which accrue to the subject denotata in (36-39). Crucially, a bounded state is not ipso facto a homogeneous activity; it is merely a state phase. By assuming that state phases and homogeneous activities are distinct situation types, we can explain why certain Progressive-form stative predications, exemplified in (40-42) are anomalous:

(40) *His hair is being green this semester.

(41) *The British Museum is containing the Parthenon Marbles right now.

(42) *She is having a cold today.

While all of the state radicals expressed by (40-42) can be described as temporary, no one of them is readily construed as a homogeneous activity. Such a construal would require that the subject denotata in these sentences be seen as effectors. If these sentences have interpretations at 
all, they require very unusual background assumptions, e.g., that the British Museum is preventing the Parthenon Marbles from leaving. Therefore, it is reasonable to conclude that participial complements in Progressive constructs do not denote states, temporary or otherwise, whether or not their head verbs are stative. Progressive predications denote states, whatever the Aktionsart of the complement denotatum. Thus, an apparent paradox - a stativizing construction accepts stative input verbs - dissolves when we recognize that the input state - by the very fact of its combination with the Progressive construction-come to denote that type which warrants the use of the Progressive construction. The reconciliation procedure which yields the dynamic interpretations of Progressive-form state predications like those in (33-35) involves the addition operator: the operator HOLD and the effector argument it projects are added to the causal representation of the input state, yielding an activity representation. This type matches the type of the participial complement in the Progressive construction.

By treating the complement of the Progressive as denoting an activity rather than a telic event, we solve a problem of semantic representation which otherwise requires recourse to stipulation. It is generally assumed that the semantics of the Progressive is intensional (see, e.g., Dowty 1977): while the Progressive combines with both telic predicates and process predicates, in the former case the culmination of the event denoted by the predicate is only a potential. For example, a Progressive sentence containing a verb of creation, e.g., She was knitting a vest, entails nothing about the knitting event having reached its logical endpoint or about the existence of the vest. As De Swart describes this situation, "The Progressive picks out a stage of [a] process/event which, if it does not continue in the real world, has a reasonable chance of continuing in some other possible world" (1998:355). This view presents a paradox, since we cannot obviously provide a semantic representation for a stage of an event while preventing the variable which represents this event from being existentially bound. It is as though we had to represent the semantics of a Partitive NP, e.g., an engine from an old Volvo, while ensuring that the entity corresponding to the term an old Volvo is not part of the discourse model. This would make little sense; we cannot extract a portion from a type whose existence is not presupposed. A possible solution to this problem is to propose that the event exists in the discourse model but that it is "stripped" of its culmination point (De Swart 1998: 355). It is not clear what this proposal would gain us, since the very existence of a telic event entails its culmination. De Swart's particular approach to the intensionality problem is to ensure through embedding that the 
event variable upon which the Progressive operates is not added to the discourse model (pp. 354355). This solution does not seem to generalize, however, because event variables representing activities (e.g., She was talking with her friends) are clearly existentially bound. How will the rule which constructs a discourse representation from a Progressive sentence know the difference between an event which should 'pop up' to main box of the representation and that which must not? The solution adopted here- - to assume that the 'input' event type is inherently processual (i.e., an activity) — avoids such problems.

Under the present proposal, a Progressive sentence like She is drawing a circle denotes a state which is a subpart not of the accomplishment type She-draw a circle but of the activity type which is entailed by the semantic representation of the accomplishment type. Since this activity can be identified with the preparatory activity that circle-drawing entails, circle-drawing can be distinguished from square-drawing etc. within the narrow window afforded by a Progressive assertion (see Parsons 1990 and Mittwoch 1988 for a compatible proposals). The only event variable which is added to the discourse model by a Progressive assertion is the activity denoted by the VP complement of the Progressive construction. Because of the subinterval property, any reasonably sized portion of this activity is sufficient to verify the occurrence of that event. The ontological nature of the situation type added to the model, and thus the nature of the commitment made by a speaker who employs a Progressive assertion, is expressed by the semantics of the Progressive construction: this construction denotes a state which holds during the time that a particular activity goes on. If I make an assertion that preparatory activity (e.g., circle drawing) was going on at some point, I say nothing about whether or not that preparatory activity led to its logical culmination (a completed circle).

But of course the representation of the Progressive construction given in Figure 6 predicts that we will induce a unification violation when we attempt to combine a telic verb or VP like draw- a circle with the construction, since the construction requires a complement denoting an activity. Only a complement with a processual denotatum, like play-cards or dance-, unifies unproblematically with the Progressive construction as represented in Figure 7. This poses a problem, since clearly telic VP complements ARE welcomed by the Progressive, as in, e.g., They were baking a fruitcake. The solution to this problem depends upon the Override Principle. I postulate that Progressive sentences containing telic VP complements are instances of coercion. In interpreting the sentence They were baking a fruitcake, the interpreter must derive an 
interpretation of the VP complement which is compatible with the activity feature that the construction imposes on its complement daughter. Since accomplishment predicates like bake- $a$ cake entail processes, the compromise interpretation will be one in which the VP complement baking a fruitcake denotes the preparatory process which leads to the existence of a fruitcake. As we observed above, this preparatory process can be verified under the same circumstances that lead to verification of the state which the Progressive sentence denotes. The Aktionsart-based permutation involved here, in which an accomplishment radical receives an activity construal, involves selection: an activity is selected from the causal representation of the input accomplishment radical. This type shift has a precedent in coercions triggered by the presence of durational adjuncts, e.g., for ten minutes. For example, the accomplishment predicate walk home receives an activity construal in (43):

She walked home for ten minutes and then decided to take the bus.

As in the case of the Progressive sentence They were baking a fruitcake, the activity denoted is entailed by the causal representation of the event radical.

What of the combination of the Progressive and an achievement radical, as in She was winning the race? This combination again yields a coerced processual interpretation of the VP complement. Our intuitions suggest that a Progressive-form achievement predication denotes a preparatory phase which is not entailed by the corresponding simple Past predication (She won the race). Dowty (1986) describes achievement verbs as "those kinesis predicates which are not only typically of shorter duration than accomplishments, [but also are not ordinarily understood] as entailing a sequence of subevents, given our usual everyday criteria for identifying the events named by the predicate" (p. 43). Our intuition that sentences like She was winning the race stretch out the temporal profile of an achievement to reveal its subevents makes sense only if we recognize such sentences as instances of coercion. Since the Progressive requires that its lexical complement denote an activity, the interpreter of a Progressive-form achievement predication is induced to 'find' an activity phase within an event which would otherwise represent a momentaneous transition. An achievement predication which entails the occurrence of a preparatory activity is for all intents and purposes an accomplishment; the sentences She was winning the race and She was fixing the fence are identical so far as the contribution of the 
Progressive is concerned. This equivalence is represented in our system by means of an indirect type shift: an activity predicate is added to the causal representation of the input achievement radical; this predicate then becomes available for selection, resulting in an activity representation.

The analysis of Progressive-form achievements offered here is a departure from standard accounts, since Progressive-form achievement predications are generally said to require iterated readings, as in She was blinking (Herweg 1991, Langacker 1991, Bickel 1997). However, such iterated readings are generally required only insofar as the noniterated reading requires unusual background assumptions - for example that a single blink can be 'tracked' during the time that it occurs. Further, the interpretive potential represented by the iterated reading is not unique to Progressive sentences containing VP complements of the achievement class. Perfective verbs of all Aktionsart classes allow iterated readings in Progressive sentences. For example, the Progressive-form accomplishment sentence She was fixing the fence and the Progressive-form activity sentence She was running both have habitual readings, which are particularly robust in conjunction with frame adverbials like that summer.

On the assumption that habitual events have the same temporal and causal representations as event chains, habitual Progressive predications have a straightforward analysis. Since the Progressive construction selects for the activity type as its complement, and a habitual event radical, e.g., They pick- up donations on Tuesdays, constitutes an activity, predicate-argument structures denoting habitual events unify directly with the Progressive construction. Combination of the Progressive with a tense construction, e.g., the Present, will yield constructs like (44):

(44) They are picking up donations on Tuesdays.

Notice that adverbial expressions which denote event repetition, e.g., on Tuesdays, or large intervals, e.g., last summer, can impose iterated-event readings upon situation radicals which might otherwise qualify as simplex events. However, as argued above, the Progressive itself is not responsible for any such implications of iteration, since those implications are present whether or not the Progressive is used, as in (45):

(45) They picked up donations on Tuesdays. 
The Progressive construction simply requires a participial complement denoting an activity, and iterated events qualify as such.

\subsection{Tense Constructions: The Present in French and English}

As has been widely noticed, the French Present construction has a wider range of uses than its English counterpart. I will argue that the divergent uses are contexts of coercion. One such use is that in which the Present construction expresses partitive (i.e., 'Progressive-style') meaning in combination with an event radical, as in (46-47):

(46) Faîtes pas attention, Mademoiselle. Il vous taquine!

"Don't pay any attention to him, miss. He's teasing you." (Binet, Les Bidochon 2, p. 7).

(47) Eh bien, à present, je me sens mieux. Le moral revient.

"Well, now I feel better. My morale is coming back." (Binet, Les Bidochon 8, p. 42)

The coerced stative interpretation in (46) is derived by selection of an intermediate rest from the temporal representation of the input activity radical $I l$ vous taquiner ('He tease- you'). The coerced stative interpretation in (47) is derived by an indirect type-shift: the input achievement representation is augmented up to an accomplishment representation via addition; the added activity representation then becomes available for selection. Thus, (47) has the same slowmotion conceptualization as its Progressive translation - the return is not immediate, but has an onset phase. The French Present construction is also used to denote a present-contiguous state phase when combined with either a state-phase or activity radical, as in (48-49), respectively:

(48) Comme moi, alors! Sauf que moi, c'est une affaire réglée depuis quinzes jours.

"Same here! Except in my case the thing [surgery] has been a done deal for fifteen days." (Binet, Les Bidochon 7, p. 25)

(49) Raymonde: Ça commence à s'éclarcir!

Robert: C'est une chance! Depuis une heure qu'on attend! 
"Raymonde: It [the waiting room] is beginning to clear out. Robert: That's a stroke of luck - considering we've been waiting for an hour." (Binet, Les Bidochon 7, p. 15)

The coerced stative readings in (48-49) involve the application of selection to the input temporal representation: the state denoted by the construction represents a posterior rest selected from the temporal representation of the input state phase or activity. The French Present construction is also used to coerce stative readings of iterated events via selection, yielding habitual and gnomic readings of event-chain radicals. These readings are exemplified for French in (50-51):

(50) Ils disent neuf heures à tout le monde. Comme ça, si t'as pas la chance de passer dans les premiers, tu attends des heures!

"They tell everyone to come at nine. That way, if you don't have the luck to get in first, you wait for hours." (Binet, Les Bidochon 7, p. 15)

(51) La pratique régulière du jogging prolonge la vie de deux à huit ans!

"Regular jogging prolongs life from two to eight years!" (Binet, Les Bidochon 11, p. 36)

As shown by the Present-tense translations in (50-51), the English Present can also coerce stative readings of event chains. However, neither the partitive nor present-contiguous state-phase readings are currently expressed by the Present construction in English. Bybee, Perkins \& Pagliucca (1994) attribute this fact to a split in the system of reporting devices in English, arguing that English now has two exponents of Present meaning: the simple Present and the Present Progressive, the latter of which "appears to have been generalizing and taking over some of the functions of the Present for several centuries" (p. 144). While I believe that this assessment of the facts is basically correct, I have a different view of the semantic implications of these facts. According to Bybee, Perkins \& Pagliucca (1994:152), the Present Progressive and Present tense participate in a privative opposition, in which the Present tense is the unmarked member: "the Simple Present carries no explicit meaning at all; it refers to the default situation from which other tenses represent deviations". Because of its bleached semantics, the Present can "absorb the meaning inherent to normal social and physical phenomena, and this meaning if described and broken down explicitly, consists of habitual occurrence and behavior as well as 
ongoing states" (ibid). The analysis appears to raise more questions than it answers. First, why should states be more "normal" than ongoing events? Second, why should a meaningless construction require a disjunctive definition, involving both ongoing states and habituals? But even leaving these concerns aside, one could not describe the aspectual constraints which the Present exhibits, and the coercion effects which it performs, if one did not view it as meaning something. I propose that the Present tense is a concord construction in both French and English. In both languages, the Present construction both denotes and invokes a state type. Unlawful combinations are 'amnestied' as per the Override Principle. The Present construction is shown in Figure 8.

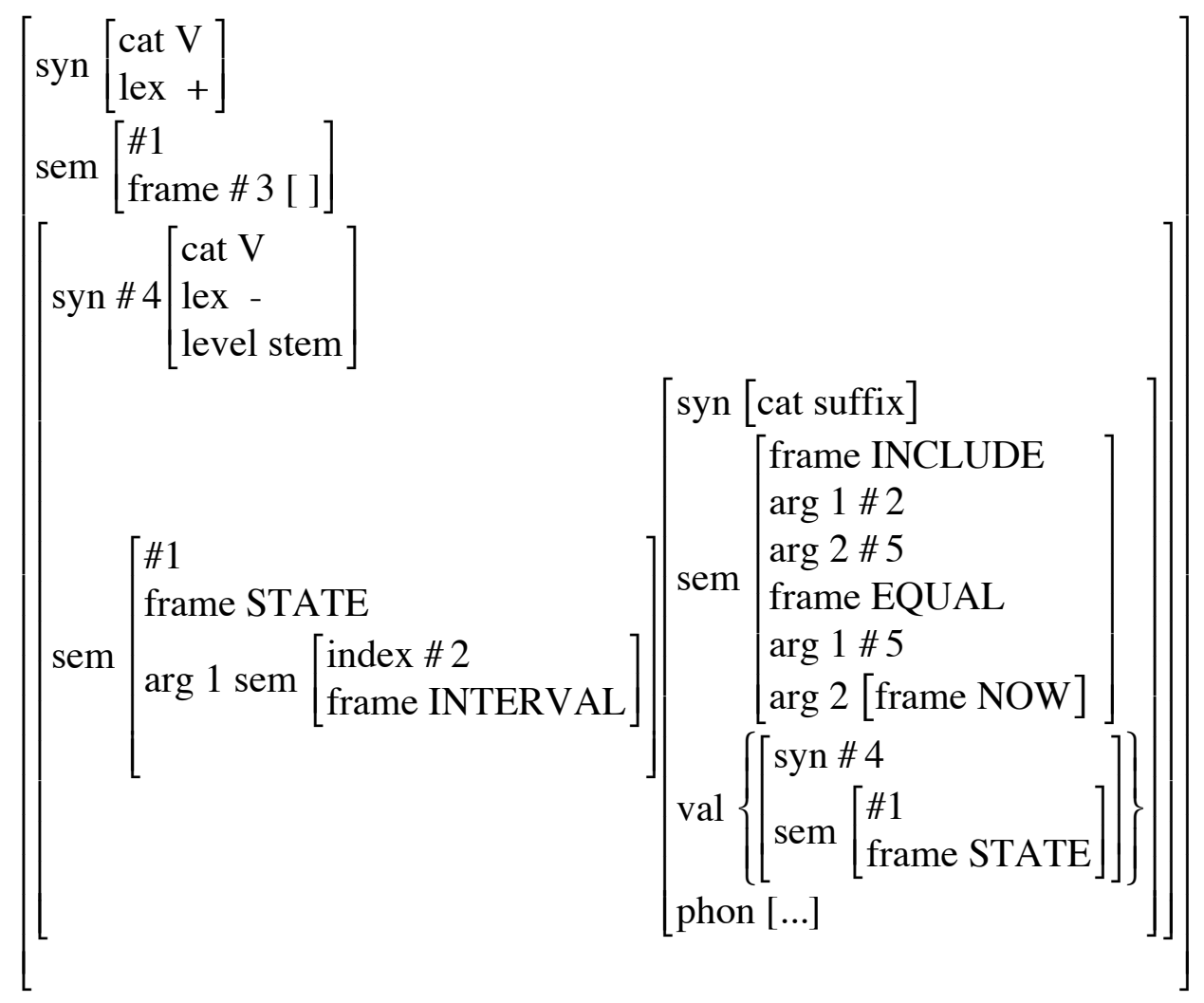

Figure 8. The Present construction

As shown in this figure, the Present construction signifies a deictic relation; the sem value of the Present suffix includes the frame EQUAL, which expresses an identity relation between reference time and the time of coding. Accordingly, this frame has two arguments, a REFERENCE TIME (indexed by the unification variable \#5) and the (deictically indexed) time of speaking. The 
frame INCLUDE, which similarly has two arguments, expresses an inclusion relationship between the situation denoted by the verbal head (which carries the unification index \#1) and reference time (an interval which carries the unification index \#5). The verbal head of the construction denotes a state, as indicated by its frame value. The STATE frame has one argument, an interval, since states are properties of times rather than individuals (Herweg 1991). As shown, the Present is a concord construction: the verbal head is a state and its complement (the tense suffix) contains a valence requirement calling for a state.

The analysis of the Present provided here differs from previous attempts to address the source of typological variation in the semantic range of the Present tense. Cooper 1986, for example, argues that the English present tense is "exotic" in requiring a higher degree of coincidence between speech and situation times than does Present inflection in other languages: "the semantic location of the present in other languages requires the discourse [time] to temporally overlap the event [time] rather than be identical with it" (p. 29). The current proposal locates the relevant typological variation elsewhere. Under this proposal, Present constructions are intrinsically state selectors. The selection behavior of the Present is a logical entailment, since speech time is a 'shallow' interval that does not provide the conditions necessary for verification of an event. The difference between the English Present and its analogs in other languages comes down to the coercive potential of each cognate construction: while all Present constructions denote stative types, the English Present limits the type shifts that input event radicals can undergo. These limitations are not predicted by the Override Principle and therefore appear to be construction-specific. Since constructions denote in the manner that words do, we expect that constructions, like words, should carry use conditions that do not follow directly from their referential properties (Michaelis 1998: ch. 3).

\section{Conclusion}

Coercion effects have been invoked in support of modular grammatical architectures, because they involve meanings which are not linguistically expressed. These same phenomena have here been interpreted in a very different way, as evidence for syntactic patterns which, like words, denote types of entities and events. We assume that the set of types denoted and evoked by constructions is a universal inventory. On this assumption, it makes sense to ask why two constructions which denote the same type, e.g., the English and French Present constructions, 
should show distinct patterns of coercion. A satisfactory answer to this question will certainly involve the effects of quantity-based inference. Where shift constructions are available to perform a given aspectual mapping, as is the Progressive in English, the mapping is unlikely to be performed by a less specialized concord construction, e.g., the Present. It remains unclear, however, what conditions favor the diachronic development of shift constructions. While the use of an explicit type-shifting devices can be viewed as a hearer-based accommodation, arising from the drive toward maximal transparency, the use of an implicit type-shifting device can be seen as a speaker-based optimization strategy, involving economy of effort. These two countervailing factors - effort conservation and informativeness - conspire to ensure a relatively balanced division of semiotic labor, as described by Horn (1984): type-shifting functions are apportioned relatively equally among shift and concord constructions in each language's inventory.

\section{References}

Bickel, Balthasar. 1997. Aspectual Scope and the Difference between Logical and Semantic Representation. Lingua 102: 115-131.

Binnick, Robert I. 1991. Time and the Verb. Oxford: Oxford University Press.

Bresnan, Joan and Sam A. Mchombo. 1995. The Lexical Integrity Principle: Evidence from Bantu. Natural Language and Linguistic Theory 13: 181-254.

Bybee, Joan. 1995. Regular Morphology and the Lexicon. Language and Cognitive Processes 10: 425-455.

Bybee, Joan, Revere Perkins and William Pagliuca. 1994. The Evolution of Grammar. Chicago: University of Chicago Press.

Cooper, Robin. 1986. Tense and Discourse Location in Situation Semantics. Linguistics and Philosophy 9:17-36.

Croft, William. 1996. What's a Head? In J. Rooryck and L. Zaring, (eds.), Phrase Structure and the Lexicon. Dordrecht: Kluwer Academic Publishers. 35-75. 
Croft, William. 1998. Event Structure in Argument Linking. In M. Butt and W. Geuder, (eds.), The Projection of Arguments. Stanford: CSLI Publications. 21-64.

De Swart, Henriette. 1998. Aspect Shift and Coercion. Natural Language and Linguistic Theory 16: $347-385$.

Dowty, David. 1977. Toward a Semantic Analysis of Verb Aspect and the English 'Imperfective' Progressive. Linguistics and Philosophy 1: 45-77.

Dowty, David. 1986. The Effects of Aspectual Class on the Interpretation of Temporal Discourse: Semantics or Pragmatics? Linguistics and Philosophy 9: 37-61.

Fillmore, Charles J., Paul Kay, Ivan Sag and Laura A. Michaelis. to appear. Construction Grammar. Stanford: CSLI Publications.

Goldberg, Adele. 1995. Constructions: A Construction Grammar Approach to Argument Structure. Chicago: University of Chicago Press.

Herweg, Michael. 1991. Perfective and Imperfective Aspect and the Theory of Events and States. Linguistics 29: 969-1010.

Horn, Laurence R. 1984. Toward a New Taxonomy for Pragmatic Inference: Q-Based and RBased Implicature. In Deborah Schiffrin, (ed.), Meaning, Form and Use in Context: Linguistic Applications. Washington: Georgetown University Press. 11-42

Israel, Michael. 1996. The Way Constructions Grow. In A. Goldberg, (ed.), Conceptual Structure, Discourse and Language. Stanford: CSLI Publications. 217-230.

Jackendoff, Ray. 1990. Semantic Structures. Cambridge, MA: MIT Press.

Jackendoff, Ray. 1997. The Architecture of the Language Faculty. Cambridge, MA: MIT Press.

Kay, Paul and Charles J. Fillmore. 1999. Grammatical Constructions and Linguistic Generalizations: The 'What's X doing Y' Construction. Language 75: 1-33.

Koenig, Jean-Pierre. 1999. Lexical Relations. Stanford: CSLI Publications. 
Langacker, Ronald W. 1987. Foundations of Cognitive Grammar, Volume 1. Stanford: Stanford University Press.

Langacker, Ronald W. 1991. Foundations of Cognitive Grammar, Volume 2. Stanford: Stanford University Press.

Langacker, Ronald W. 1994. A Constraint on Progressive Generics. In A. Goldberg, ed., Conceptual Structure, Discourse and Language. Stanford: CSLI Publications. 289-302.

Levin, Beth and Tova Rapoport. Lexical Subordination. 1988. Chicago Linguistics Society 24. 275-289.

Michaelis, Laura A. 1994. A Case of Constructional Polysemy in Latin. Studies in Language 18: 45-70.

Michaelis, Laura A. 1998. Aspectual Grammar and Past-time Reference. London: Routledge.

Michaelis, Laura A. and Knud Lambrecht. 1996. Toward a Construction-based Theory of Language Function: The Case of Nominal Extraposition. Language 72: 215-247.

Michaelis, Laura A. and Josef Ruppenhofer. 2001. Beyond Alternations: A Constructional Model of the Applicative Pattern in German. Stanford: CSLI Publications.

Mittwoch, Anita. 1988. Aspects of English Aspect: On the Interaction of the Perfective, Progressive, and Durational Adverbials. Linguistics and Philosophy 11: 203-254.

Mourelatos, Alexander. 1978. Events, Processes and States. Linguistics and Philosophy 2: 415434.

Parsons, Terence. 1990. Events in the Semantics of English. Cambridge, MA: MIT Press.

Partee, Barbara. 1984. Nominal and Temporal Anaphora. Linguistics and Philosophy 7: 243-286

Partee, Barbara. 1991. Adverbial Quantification and Event Structures. Berkeley Linguistics Society 17: 439-456. 
Rappaport Hovav, Malka and Beth Levin. 1998. Building Verb Meanings. In M. Butt and W. Geuder, (eds.), The Projection of Arguments. Stanford: CSLI Publications. 97-134.

Smith, Carlota. 1997. The Parameter of Aspect. Dordrecht: Kluwer Academic Publishers.

Van Valin, Robert D. and Randy LaPolla. 1997. Syntax: Structure, Meaning and Function. Cambridge: Cambridge University Press.

Vlach, Frank. 1981. The Semantics of the Progressive. In P. Tedeschi and A. Zaenen, (eds.), Syntax and Semantics, volume 14. New York: Academic Press, Inc. 415-434.

Zwicky, Arnold. 1985. Heads. Journal of Linguistics 21: 1-29.

Zwicky, Arnold 1994. Dealing out Meaning: Fundamentals of Grammatical Constructions. Berkeley Linguistics Society 20.

\section{Endnotes}

${ }^{1}$ The idea that constructional requirements may override lexical requirements in the case of NPs like $a$ beer is not part of the conception of Construction Grammar put forth in Kay \& Fillmore 1999. In that version of the model, conflict of this type would represent a unification failure, since the [bounded-] feature of the noun beer would conflict with the [bounded+] requirement that the Indefinite Determination construction imposes upon its nominal daughter. Therefore, the licensing of tokens like a beer requires the intercession of TYPE-SHIFTING constructions. A typeshifting construction has an EXTERNAL SEMANTIC VALUE which is distinct from that of it sole daughter node. The Mass $>>$ Count construction, for example, unifies with a mass noun like beer. Its external semantics is that of a count noun, which can thereby unify with Indefinite Determination. Type-shifting constructions are essentially lexical rules, and as such fail to capture an important generalization, since type-shifted nominals are freely generated but not indexed to the morphosyntactic contexts which trigger the relevant type shifts. Further, use of the 'box-within-a-box' constructions for type-shifting violates the spirit of a model which, in the interest of concreteness, eschews nonbranching domination in phrase structure. That is, in CG, 
no phrase consists simply of a noun. If a given lexical noun is of the appropriate semantic class, it will simply unify directly with any grammatical-function position in a construction. In accordance with Goldberg (1995), I therefore employ a version of the CG architecture which allows for unification with overrides, as per the Override Principle to be described in Section 2.

${ }^{2}$ In a construct - a linguistic string licensed by a unified combination of constructions - any unspecified values (as for the maximality attribute of a mass noun) will be 'filled in', as Definite Determination imposes a [max-] value on its nominal daughter.

${ }^{3}$ See Zwicky (1995) for a discussion of construction-based grammar as a model of nonlocal licensing relationships (e.g., "niece licensing", in Zwicky's terms) and exocentric determination of syntactic category membership.

4 The maximality-based model in CG targets the same combinatory constraint that X-bar syntax captures by requiring that sisters to lexical heads be phrases. However, while the term maximality suggests a model based upon phrasehood, being maximal is not equivalent to being a phrase. The maximal word water in She drank water is not 'both' a noun and a noun phrase. The syntactic context plays no role in determining whether the nominal water is more appropriately categorized as a phrase or as a bare noun. It is always merely a noun, whether it receives the value $[\max +]$, via unification with the VP construction, or the value [max-], via unification with the Definite Determination construction. See Kay \& Fillmore (1999:10) for discussion.

5 The label SM-determination refers to the construction which combines the unstressed determiner some with a nominal head denoting a mass type, as in (2b) above.

${ }^{6}$ The category of state phase should not be confused with that of STAGE-LEVEL PREDICATIONS, as described by Partee (1991), inter alia. State-level predications denote temporary states like being on sale, on fire or angry. Stage-level predications, unlike state phases, have stative syntactic and 
interpretive behaviors, e.g., they are reportable by means of the simple Present in English (e.g., Tomatoes are on sale) and interpretable as including a past reference time, as in (a):

(a) When I got to the supermarket, all the tomatoes were on sale.

7 The mapping which shifts states to state phases, while unproblematic at the level of causal structure, presents a problem for temporal representation. At the level of causal structure this mapping involves the addition of the operator HOLD, a single component of causal representation. This mapping conforms to the constraint on minimal transitions. At the level of temporal representation, however, this mapping violates the constraint on minimal transitions, since it involves the addition of TWO components of temporal representation: the onset and offset transitions. Bickel (1997:124-126) solves this problem by assuming that the temporal representations of states include an onset transition. Under this assumption, the shift to an episodic reading involves only the addition of a single (terminal) transition. Since, however, this solution neutralizes the grammatically relevant distinction between state and achievement representations, I do not adopt it here.

${ }^{8}$ As observed by Dowty (1986:43-44) and Van Valin \& LaPolla (1997), among others, aspectual types are expressed by predicate-argument combinations, rather than lexical verbs. However, I will assume, following Dowty, that the aspectual type of the verb is derivable from the type of its projection, whether this projection be a verb phrase or sentence. Because all information conveyed by attribute-value matrices is available at every node in a construct (a licensed combination of constructions), the semantic type information contributed by the verb's arguments is in the valence set of the verb. Therefore, the information necessary to perform aspectual categorization will always be available at the level of the verb. Information sharing obviates the need for us to propose that aspectually sensitive adjuncts are adjoined to sentences or VPs. This move would have no obvious rationale in the syntax and would serve solely to ensure that the adjunct has a sister to which the relevant aspectual features can accrue. 
9 While the complement of the Progressive auxiliary be belongs to the syntactic category VP, its semantic type is that of event. Via coinstantiation, the subject requirement of the head verb of the VP complement is satisfied, i.e., 'accounted for', since it unifies with the NP which serves as subject of the finite auxiliary. Notice that we need not assume, as is traditional in the transformational tradition, that the complement of the auxiliary is 'syntactically' a sentence.

${ }^{10}$ As we have seen, the activity class includes not only homogeneous activities of the sleep-type but also events of the run-type, consisting of iterated subevents. This division within the activity class leads us to predict that Progressive-form stative predications may have readings otherwise associated with heterogeneous activity sentences. It would appear at first glance that progressivized state sentences which express the accretion of a property have such readings:

(a) I'm believing your story more and more.

(b) I'm seeing the picture with increasing clarity.

(c) I'm liking each song more than the last one.

The fact that the stative verbs in (a-c) are paired with comparative adverbials, e.g., more and more, suggests that they have heterogeneous-activity readings, since ordinarily only heterogeneous activities are compatible with such adverbials, as in (d):

(d) She ran faster and faster.

Adverbials denoting 'accretion' of a gradient property are incompatible with telic predications, as shown by the ill formedness of (e):

(e) * She broke the glass faster and faster.

Such adverbials are also incompatible with state radicals, as shown by the ill formedness of (f):

(f) * She is a French professor more and more. 
However, the comparative adverbials in (a-c) need not be taken as symptomatic of a construal imposed by the Progressive construction. Instead, these adverbials can be viewed as themselves coercing activity readings. For example, a predication whose head is a state verb denotes a set of iterated episodes (i.e., an event chain) when combined with a comparative adverb:

(g) She liked that song more each time she heard it.

It could be argued that $(\mathrm{g})$ constitutes a state sentence rather than an activity sentence, since it could as easily be presented in the simple present tense, as in (h):

(h) She likes that song more each time she hears it.

As I will argue below, however, the mere fact of co-occurrence with the Present tense is not evidence of stativity, since the Present tense can coerce stative readings of otherwise perfective predications. For this reason, I will reject Langacker's (1994) division between habitual sentences, as in (h), and repeated-event sentences, as in (g). Both (g) and (h) represent iteratedevent sentences, i.e., activities. In the case of (h), however, the Present construction has imposed a state reading on what would otherwise be an activity radical. 